\title{
Nanoparticles for intravascular applications: physicochemical characterization and cytotoxicity testing
}

\begin{abstract}
Aim: We report the physicochemical analysis of nanosystems intended for cardiovascular applications and their toxicological characterization in static and dynamic cell culture conditions. Methods: Size, polydispersity and $\zeta$-potential were determined in 10 nanoparticle systems including liposomes, lipid nanoparticles, polymeric and iron oxide nanoparticles. Nanoparticle effects on primary human endothelial cell viability were monitored using real-time cell analysis and live-cell microscopy in static conditions, and in a flow model of arterial bifurcations. Results \& conclusions: The majority of tested nanosystems were well tolerated by endothelial cells up to the concentration of $100 \mu \mathrm{g} / \mathrm{ml}$ in static, and up to $400 \mu \mathrm{g} / \mathrm{ml}$ in dynamic conditions. Pilot experiments in a pig model showed that intravenous administration of liposomal nanoparticles did not evoke the hypersensitivity reaction. These findings are of importance for future clinical use of nanosystems intended for intravascular applications.
\end{abstract}

First draft submitted: 9 October 2015; Accepted for publication: 18 December 2015; Published online: 22 March 2016

Keywords: atherosclerosis $\bullet$ endothelial cells $\bullet$ hypersensitivity reaction $\bullet$ live-cell analysis - nanoparticle biocompatibility • nanoparticle stability

Atherosclerosis and consecutive cardiovascular events represent one of the biggest global health problems [1]. Rupture of vulnerable atherosclerotic plaques can lead to ischemia of the heart, brain or extremities [2], the predominant causes of morbidity and mortality worldwide. Although both the understanding of disease mechanisms and the imaging techniques for atherosclerotic plaque detection have considerably advanced during the last decades, effective approaches to early diagnosis and improved targeted therapies are still missing [3].

The potential of nanotechnology-based therapies to overcome the disadvantages of systemic drug administration has been well recognized in the field of oncology, but no specific nanoparticle-based system has yet been approved for diagnosis or therapy of cardiovascular diseases. By coating nanopar- ticles with plaque-specific ligands, significantly increased accumulation of these agents at the sites of atherosclerotic lesions could be achieved, leading to improved detection and characterization of the plaques [4]. Furthermore, the treatment outcome can be dramatically improved if the drug-carrying nanoparticles were directly targeted at the diseased artery region, thus reducing the systemic side effects [5]. Hence, our goal is the development of effective, safe and innovative nanoparticle-based systems for the diagnosis and therapy of clinically relevant atherosclerosis. For this purpose, systematic analyses of the candidate nanosystems including their basic physicochemical characterization, their long-term stability and the biological effects of nanoparticles, for example, on the vascular cells, are necessary. So far, the majority of studies utilized fibroblasts, mesenchymal
Jasmin Matuszak', Jens Baumgartner², Jan Zaloga', Maya Juenet ${ }^{3}$, Acarília Eduardo da Silva ${ }^{4}$, Danielle Franke5, Gunter Almer6, Isabelle Texier?, Damien Faivre², Josbert M Metselaar ${ }^{4,8}$, Fabrice P Navarro7, Cédric Chauvierre ${ }^{3}$, Ruth Prassl ${ }^{9}$, László Dézsi ${ }^{10}$, Rudolf Urbanics ${ }^{11}$, Christoph Alexiou', Harald Mangge ${ }^{6}$, János Szebeni10,11, Didier Letourneur ${ }^{3}$ \& Iwona Cicha*,1 ${ }^{1}$ Cardiovascular Nanomedicine Unit, Section of Experimental Oncology and Nanomedicine (SEON), ENT-Department, University Hospital Erlangen, Glückstr. 10a, 91054 Erlangen, Germany ${ }^{2}$ Department of Biomaterials, Max Planck Institute of Colloids \& Interfaces, Science Park Golm, Potsdam, Germany ${ }^{3}$ Inserm U1148, LVTS, Paris Diderot University, Paris 13 University, Sorbonne Paris Cité, X. Bichat Hospital, Paris, France ${ }^{4}$ Department of Targeted Therapeutics, MIRA Institute, University of Twente, Enschede, The Netherlands ${ }^{5}$ nanoPET Pharma GmbH, Berlin, Germany ${ }^{6}$ Clinical Institute of Medical \& Chemical Laboratory Diagnostics, Medical University of Graz, Graz, Austria ${ }^{7}$ CEA-LETI MINATEC/DTBS, Université Grenoble Alpes, Grenoble, France ${ }^{8}$ Department of Experimental Molecular Imaging, University Clinic \& Helmholtz Institute for Biomedical Engineering, RWTHAachen University, Aachen, Germany Institute of Biophysics, Medical University of Graz, Graz, Austria ${ }^{10}$ Nanomedicine Research \& Education Center, Semmelweis University, Budapest, Hungary "SeroScience Ltd., Budapest, Hungary

*Author for correspondence:

Tel.: +499131 8543953

Fax: +49 91318534282

Iwona.Cicha@uk-erlangen.de

Future $\because$ Medicine part of 
stem cells or cancer cells to investigate the biocompatibility of nanosystems. In the recent years, increased numbers of publications appeared concerning the possible interactions between nanoparticles and endothelial cells, which are the first contact cells in the vascular wall for circulating nanoparticles. However, these reports usually focus on one type of nanosystems in the context of endothelial viability, or barrier function [6-9]. Thus, the purpose of this work was to perform comparative physicochemical and biological analyses of different types of nanoparticles intended for intravascular applications.

The candidate nanosystems included in these analyses comprise lipid nanoparticles, liposomes, polymeric nanoparticles, as well as inorganic nanoparticles, that are briefly outlined below.

Lipid nanoparticles (Lipidots ${ }^{\mathrm{TM}}$ ) can be considered as nano-oil droplets stabilized by a mixture of surfactants (oil-in-water emulsion). They are composed of a lipid core, herein a mixture of soybean oil and a wax, and a surfactant shell, containing a mixture of phospholipids and polyethylene glycol (PEG)-ylated surfactants [10]. Liposomes are composed of a lipid bilayer consisting of amphipathic phospholipids (primarily phosphatidylcholine) that enclose an interior aqueous space [11]. The head groups of phospholipids are often functionalized with polymerizable moieties to improve stability (e.g., PEGylated stealth liposomes [12]), or with molecular groups, which allow conjugation to antibodies or other ligands. Among the advantages of lipid nanoparticles and liposomes as drug-delivery platforms are the ease of preparation, and the reported low immunogenicity $[13,14]$, which is expected to enable safe and repeated administration.

Polymeric nanoparticles are composed of polymers, most commonly poly(lactic-co-glycolic acid), poly(lactic acid), poly(caprolactone), poly(alkylcyanoacrylates) or chitosan. The core of the nanoparticles used in our studies ( $~ 80 \%$ of the total mass) is made of poly(isobutylcyanoacrylate) (PIBCA), which is covalently cross-linked with polysaccharides of the coating, forming a hydrophilic shell. Functionalization of these nanoparticles allows conjugation of targeting ligands, for example, fucoidan, a mimic of sialyl Lewis $\mathrm{X}$, the natural ligand of P-selectin $[15,16]$, a promising molecule to target processes upregulated during destabilization of vulnerable plaques. Inorganic nanoparticle systems included in this work comprised superparamagnetic iron oxide nanoparticles. These particles consist of an iron oxide core, which is coated with organic materials such as fatty acids, polysaccharides or polymers. Iron oxide nanoparticles have good biocompatibility and contrast-enhancing properties in MRI, enabling plaque detection and characterization [17-20]. Furthermore, the magnetic properties of these particles could allow their remote targeting by means of external magnetic field [21-23].

Although the concept of nanomedicine encompasses a localized delivery of nanosystems to the diseased organs or target tissues and minimized systemic side effects, the extended circulation time, as well as multiple degradation products, may result in nanoparticle cytotoxicity [24], or immunogenicity [25]. Hence, in order to predict in vivo responses, the toxicity of any nanosystem should first be evaluated on cultured cells (e.g., endothelial cells in the case of intravenous application, and the target cells), preferably under conditions that resemble the physiological state. Although standard cytotoxicity assays have been commonly used to estimate the cellular responses to various nanosystems, many nanoparticles interfere with the available photometric assays, which may render the experimental results difficult to assess and interpret [26]. Here, we compare nanosystems' biological effects on primary human endothelial cells, using two complementary methods for long-term in vitro monitoring in static conditions (real-time cell analysis and live-cell microscopy), as well as an in vitro model of arterial bifurcation that allows observation of endothelial cells under physiologic-like flow conditions. Furthermore, we report the initial results of the pilot studies on the complement activation-related pseudoallergy (CARPA) upon the intravenous administration of liposomal nanoparticles in a pig model.

\section{Materials \& methods}

In total, ten nanoparticle systems were synthesized and investigated, including two types of liposomes (LPNPs), three types of lipid nanoparticles (LD-NPs), two types of polymeric nanoparticles (PM-NPs) and three types of iron oxide nanoparticles (IO-NPs). The detailed description of nanoparticle characterization is provided in the Online Supplement.

\section{Reagents}

Soybean oil and Myrj ${ }^{\mathrm{TM}}$ s40 (PEGylated surfactant) were purchased from Croda, Chocques, France. Lipoid S75 and dipalmitoylphosphatidylcholine were from Lipoid GmbH, Ludwigshafen, Germany. Suppocire NB was from Gatefosse, Saint-Priest, France. 1-palmitoyl-2-oleoyl-sn-glycero-3-phosphocholine (POPC), cholesterol, 1,2-distearoyl-sn-glycero-3-phospho-ethanolamine-N-[methoxy (polyethylene glycol)-2000] (DSPE-PEG-2000) and 1,2-distearoyl-phosphatidylethanolamine-methyl-polyethyleneglycol conjugate-550 (DSPE-PEG550) were purchased from Avanti Polar Lipids, Inc. (AL, USA). 
Dextran T70 was from Roth (Karlsruhe, Germany), or from Amersham Pharmacia Biotech (Freiburg, Germany), and dextran T40 from PharmaCosmos (Holbaek, Denmark). Carboxymethyl-dextran sodium salt (CM-Dextran) was purchased from Sigma Aldrich (Saint Quentin Fallavier, France) and diethylaminoethyl-dextran 20 (DEAE-dextran) from TdB Consultancy (Uppsala, Sweden). Low molecular weight Fucoidan (3-8 kDa, Fucoidan Ascophyscient ${ }^{\circledR}$ ) was from Algues et Mer (Ouessant, France). IBCA (isobutylcyanoacrylate, Glue 368) was from Orapi (Saint-Vulbas, France). Bovine serum albumin (BSA) and iron (II) chloride tetrahydrate were from Merck, Darmstadt, Germany. Lauric acid, epichlorohydrin and dextranT6 $(\mathrm{Mw}=6 \mathrm{kDa})$ were from Sigma Aldrich, Munich, Germany. Ceric (IV) ammonium nitrate and tri-sodium citrate dihydrate were purchased from Fluka (Saint Quentin Fallavier, France). $\mathrm{NaOH}, \mathrm{HCl}(25 \%), \mathrm{NH}_{3}$ $(25 \%)$ and nitric acid $(65 \% \mathrm{w} / \mathrm{w})$ were from Roth. Iron (III) chloride hexahydrate was purchased from SigmaAldrich or from Roth. All compounds used were of pharmaceutical (Ph. Eur) or highly pure $(\geq 99 \%)$ grade and were used without any further purification.

\section{Nanoparticle synthesis \\ Lipidots}

Lipid nanoparticles (LD-NP) were prepared by the sonication method [10]. Briefly, the lipid phase was prepared by mixing Suppocire ${ }^{\mathrm{TM}} \mathrm{NB}$, soybean oil and lipoid S75. The aqueous phase, containing Myrj s40 (PEGylated surfactant) in phosphate buffered saline (PBS), was heated to $50^{\circ} \mathrm{C}$ to melt the surfactant and then mixed with the lipid phase. Following sonication for $5 \mathrm{~min}$, the samples were dialyzed against PBS and sterilized by filtration through a $0.22 \mu \mathrm{m}$ filter. The batches of particles with specified diameter were obtained by altering the lipid and surfactants ratios. Three different sizes (diameters) were formulated: $50 \mathrm{~nm}$ (LD-NP1), $80 \mathrm{~nm}$ (LD-NP2) and $120 \mathrm{~nm}$ (LD-NP3).

\section{Liposomes}

For the synthesis of sterically stabilized PEGylated liposomes (LP-NP1), POPC, cholesterol (Avanti Polar Lipids) and DSPE-PEG-2000 were used. Lipids were dissolved in chloroform-methanol 2:1 (v/v) at molar ratios of 3:2:0.15. LP-NP1 were made using a dry film rehydration technique, followed by size extrusion, as described previously $[12,27]$. Briefly, the organic solvent was evaporated under a stream of nitrogen to obtain a lipid film. For complete removal of solvents the film was dried in a vacuum chamber overnight. Subsequently, the dry lipid film was hydrated in PBS and size-extruded using an Avanti Polar mini-extruder
(Avanti Polar Lipids, Inc.) and $100 \mathrm{~nm}$ polycarbonate membranes.

The LP-NP2 liposomes were prepared using the lipid injection method, by mixing the ethanolic lipid solution with the aqueous phase under magnetic stirring at $60^{\circ} \mathrm{C}$. Briefly, dipalmitoylphosphatidylcholine, cholesterol (BUFA, Uitgeest, The Netherlands), and DSPEPEG550 were dispersed in ethanol at molar ratios of 1.85:1:0.15. Subsequently, the lipid solution was transferred into PBS previously heated to $60^{\circ} \mathrm{C}$. The resulting emulsion was downsized by multiple extrusion steps through polycarbonate filter membranes with decreasing pore sizes of (200-100 nm). Subsequently, ethanol and dissolved lipids were removed by dialysis against PBS.

\section{Polymeric nanoparticles}

Polymeric nanoparticles (PM-NP) were synthesized by a redox radical emulsion polymerization method. This method ensures the polysaccharides of the shell to assemble into a brush-like layer of coating. Here, two different coatings were used: $90 \%$ CM-Dextran/10\% Fucoidan (PM-NP1); and 80\% DextranT70 (Pharmacia Biotech $/ 10 \%$ DEAE-dextran $/ 10 \%$ Fucoidan (PM-NP2). Briefly, polysaccharides $(0.1375 \mathrm{~g})$ were dissolved in a nitric acid solution $\left(2 \times 10^{-1} \mathrm{M}\right)$ at $40^{\circ} \mathrm{C}$ and left under nitrogen bubbling for $10 \mathrm{~min}$. Polymerization was initiated by adding $2 \mathrm{ml}$ ceric (IV) ammonium nitrate solution $\left(8 \times 10^{-2} \mathrm{M}\right)$ in nitric acid and $0.5 \mathrm{ml}$ of IBCA monomers to the polysaccharide solution under nitrogen atmosphere and vigorous stirring. The reaction was then left for $40 \mathrm{~min}$ at $40^{\circ} \mathrm{C}$ under gentle stirring, followed by cooling to room temperature. Subsequently, $1.25 \mathrm{ml}$ of a trisodium citrate dihydrate solution $(1.02 \mathrm{M})$ was added to the suspension and the $\mathrm{pH}$ was adjusted to 7.0 with $\mathrm{NaOH}$. PM-NPs were purified by dialysis (molecular weight cut-off 100 $\mathrm{kDa}$ ) against water. One final dialysis was performed against $\mathrm{NaCl} 0.9 \%$. Nanoparticles were sterilized by filtration through a $0.45 \mu \mathrm{m}$ filter, followed by $15 \mathrm{~min}$ exposure to UV radiation.

\section{Iron oxide nanoparticles (IO-NP)}

Lauric acid/BSA-coated magnetite nanoparticles (IONP1) were synthesized by coprecipitation, subsequent in situ coating with lauric acid and formation of an artificial albumin corona as previously described [28]. Briefly, Fe (II) and Fe (III) salts at a defined molar ratio $\left(\mathrm{Fe}^{3+} / \mathrm{Fe}^{2+}=2\right)$ were dissolved in $20 \mathrm{ml}$ of water and stirred at $80^{\circ} \mathrm{C}$ under argon atmosphere, followed by addition of $20 \mathrm{ml}$ of $\mathrm{NH}_{3}$ solution (25\%). The solution was heated to $90^{\circ} \mathrm{C}$ and $1.25 \mathrm{~g}$ lauric acid, dissolved in acetone, was added. The brownish suspension was left to homogenate for $30 \mathrm{~min}$ at $90^{\circ} \mathrm{C}$. The suspen- 
sion was then dialyzed multiple times against water. Subsequently, IO-NP1 were stabilized by incubation with a freshly prepared $20 \%$ BSA solution, purified by centrifugal ultrafiltration (molecular weight cutoff $100 \mathrm{kDa}$ ), and sterilized by filtration through a $0.22 \mu \mathrm{m}$ filter.

For preparation of dextran-coated magnetite nanoparticles (IO-NP2), the synthesis method by Unterweger et al. was used [29]. Briefly, Fe (II) and Fe (III) salts in molar ratios $\left(\mathrm{Fe}^{3+} / \mathrm{Fe}^{2+}=2\right)$ as well as $1.75 \mathrm{~g}$ of dextranT6 were dissolved in water. After cooling to $4^{\circ} \mathrm{C}$ under continuous stirring and argon atmosphere, $5 \mathrm{ml}$ of ice-cold $25 \% \mathrm{NH}_{3}$ was added. After 5 min, the reaction mixture was heated and kept at $75^{\circ} \mathrm{C}$ for a further $40 \mathrm{~min}$, followed by cooling to RT and dialysis (molecular weight cut-off $8 \mathrm{kDa}$ ). The mixture was then cleared from excess dextran and concentrated to a total volume of $20 \mathrm{ml}$ using ultrafiltration (molecular weight cut-off $100 \mathrm{kDa}$ ). To stabilize the dextran coating, crosslinking was performed by adding $4 \mathrm{ml}$ of epichlorohydrine dropwise to the nanoparticle suspension after alkalization with $\mathrm{NaOH}$ under vigorous stirring for $24 \mathrm{~h}$. The solution was then dialyzed against water, concentrated by ultrafiltration and sterile filtered through $0.22 \mu \mathrm{m}$ membrane.

IO-NP3 nanoparticles were also synthesized by the coprecipitation method. Briefly, Fe (II) and Fe (III) salts at a defined molar ratio $\left(\mathrm{Fe}^{3+} / \mathrm{Fe}^{2+}=2\right)$ were dissolved in water under nitrogen atmosphere, followed by addition of a preheated strong alkali solution under continuous stirring. In the second step, the coating material (carboxydextran) was added to the aqueous suspension of iron oxide nanoparticles followed by heating under reflux. After cooling, the resulting material was filtered and dispersed in water, followed by dialysis against water, and sterile filtration using a $0.45 \mu \mathrm{m}$ filter.

\section{Physicochemical characterization \& stability on storage}

Z-averaged hydrodynamic diameter, polydispersity (PDI) and $\zeta$-potential were determined with a Zetasizer Nano ZS (Malvern) using standard polystyrene cuvettes and disposable folded capillary cells (DTS1070), respectively. All samples were diluted prior to the measurement according to the producers' instructions: LD-NPs, LP-NP1 suspensions were diluted $10 \times$ in deionized and $0.2 \mu \mathrm{m}$-membrane filtered water, LP-NP2 were diluted $10 \times$ in PBS $\mathrm{pH} 7.4$, and PM-NPs and IO-NPs were diluted between $50 \times$ and $100 \times$ in ultrapure water. Samples were equilibrated to $25^{\circ} \mathrm{C}$ and $3 \times>10$ runs of $10 \mathrm{~s}$ performed in $173^{\circ}$ backscatter mode. The employed refractive indices and absorption coefficients for the different particles systems were: LD-NPs, 1.5, 0.1; LP-NP1, 1.4, 0.001; LP-NP2, PM-NPs, 1.59, 0.01; IO-NPs, 2.9, 5.18. To determine sample stability, the first time-point for physicochemical characterization was set at 1 month post synthesis date, followed by the subsequent measurements after 3 and 6 months of storage at $4^{\circ} \mathrm{C}$. The detailed description of further characterization methods relevant for the respective nanoparticle types is provided in the Online Supplement.

\section{Real-time cell analysis}

Human umbilical vein endothelial cells (HUVECs) were isolated from freshly collected umbilical cords (kindly provided by the Department of Gynaecology, University Hospital Erlangen) and cultured as described in the Online Supplement. In all experiments, HUVECs at passage 1-2 were used. The use of human material was approved by the local ethics committee at the University Hospital Erlangen (review number 237_12B from 19.09.2012). For monitoring the effects of nanoparticles on HUVEC viability, the xCELLigence system (RTCA DP Analyzer, Roche Diagnostics, Mannheim, Germany) was used [30]. Experiments were performed in 16-well E-plates (ACEA Bioscience, CA, USA), in which the impedance is measured with the help of microelectrodes localized at the bottom of the wells (for detailed description, see Online Supplement).

For the background measurement, $100 \mu \mathrm{l}$ of cellfree endothelial cell growth medium was added to the wells. Afterwards, $50 \mu \mathrm{l}$ of media from each well were replaced with $50 \mu \mathrm{l}$ of cell suspension containing $1 \times 10^{3}$ HUVECs. About $30 \mathrm{~min}$ after seeding of the cells, monitoring of impedance by the xCELLigence system was initiated. At $24 \mathrm{~h}$ after seeding, an additional $100 \mu \mathrm{l}$ of media containing different concentrations of nanoparticles were added to the wells, as follows: (a) for controls, $100 \mu$ l of pure medium without nanoparticles, and (b) for the treatment samples, $100 \mu \mathrm{l}$ of medium containing nanoparticles at concentrations $2 \times$ higher than the required final nanoparticle concentration. The final nanoparticle concentrations were as follows: $0,12.5,25,50,100,200$ and $400 \mu \mathrm{g} /$ $\mathrm{ml}$. Concentrations for iron oxide nanoparticles were calculated as total iron $(\mathrm{Fe})$ concentration. The concentrations for lipid nanoparticles, liposomes and polymeric nanoparticles were calculated as total dry mass weight per volume. Cell growth was monitored every $10 \mathrm{~min}$ for $96 \mathrm{~h}$. The experiments were performed in hexaplicate.

\section{Live-cell microscopy}

HUVECs were seeded in 96-well plates at $2 \times 10^{3}$ cells/well in $100 \mu \mathrm{l}$ medium. At $24 \mathrm{~h}$ after seeding, additional $100 \mu \mathrm{l}$ of media containing different con- 
centrations of nanoparticles were added to the wells, as described in detail above. Cell growth was monitored for $72 \mathrm{~h}$ using a live cell-imager (IncuCyte FLR microscope system, Essen Bioscience, MI, USA). The experiments were performed in hexaplicate.

\section{Flow experiments}

Flow experiments were performed as previously described (see [31] and Online Supplement). For the perfusion with nanoparticles, two different concentrations were used $(100 \mu \mathrm{g} / \mathrm{ml}$ and $400 \mu \mathrm{g} / \mathrm{ml})$. Subsequently, HUVECs were stained with Alexa488phalloidin (PromoKine, Heidelberg, Germany). Cell nuclei were counterstained with DAPI (Molecular Probes, Darmstadt, Germany). Images were obtained using fluorescence microscope Zeiss Axio Observer. Z1 (Carl Zeiss AG, Oberkochen, Germany). The confluence was determined on $\times 10$ objective magnification images using ImageJ software.

\section{Pig model of complement activation-related pseudoallergy (CARPA)}

Pilot studies in a pig model of infusion reaction to LP-NP1 were performed as described by Szebeni [32]. Briefly, domestic male Yorkshire pigs $(20-25 \mathrm{~kg}$ ) were anesthetized with isoflurane $\left(2-3 \%\right.$ in $\mathrm{O}_{2}$ ). Intubation was performed with endotracheal tubes to maintain free airways. Oxygen saturation was monitored using a pulse-oximeter fixed on the tail, and body temperature was monitored rectally. A capnograph was connected to the tracheal tube to monitor $\mathrm{EtCO}_{2}$ and the respiratory rate (CAP10, Medlab GmbH, Karlsruhe, Germany). To measure the pulmonary arterial blood pressure (PAP), a Swan-Ganz catheter (AI-07124, 5 Fr. 110 $\mathrm{cm}$, Arrow International, Inc., Teleflex, Athlone, Ireland) was introduced into the pulmonary artery via the right external jugular vein - right atrium - right ventricle, while systemic arterial blood pressure (SAP) was measured in the femoral artery. LP-NP1 and zymosan were injected in the animals in bolus $(<10 s)$ via the left external jugular vein. The amount of test material injected is given as $\mathrm{mg}$ phospholipids $/ \mathrm{kg}$, unless otherwise indicated. Hemodynamic changes were continuously monitored at $1000 \mathrm{~Hz}$ sampling rate, using an AD Instruments PowerLab System with LabChart Pro v6 software. From the mean PAP, SAP and heart rate (HR) data about $20 \mathrm{~s}$ intervals were averaged and evaluated by AD Instruments LabChart Pro v6 software modules. The usual evaluated periods were: before the test material injection, then $20 \mathrm{~s}$ in every minute for $10 \mathrm{~min}$, and every $5 \mathrm{~min}$ until the end of the reaction. Plasma levels of thromboxane B2 (TXB2, the stable metabolite of TXA2) were measured with a commercially available ELISA kit (Cayman Chemi- cals, MI, USA). The study was approved by the local ethics committee for animal experimentation.

\section{Statistical analyses}

The differences between the in vitro treatment groups were calculated using ANOVA on Ranks. Data were expressed as mean \pm SEM, unless stated otherwise. In vivo changes in SAP and $\mathrm{HR}$, as well as TXB2 were compared with time 0 (baseline) values using one-way ANOVA with Dunnett's post hoc test. $\mathrm{p}<0.05$ was considered statistically significant.

\section{Results}

Nanoparticle characterization \& stability on storage

The detailed description of physicochemical properties of respective nanoparticles is provided in the Online Supplement (Supplementary Figures 1-16, see also $[10,12,27-29])$. To validate the stability of physicochemical parameters upon prolonged storage, the Z-averaged hydrodynamic diameter, the polydispersity (expressed as polydispersity index, PDI) and the $\zeta$-potential of the investigated nanoparticles were determined at different time points. The first collective analysis time-point was set at 1-month post synthesis date. The detailed characteristics of the nanoparticles are shown in Table 1. To ensure the long-term particle stability, subsequent measurements were performed on the various nanoparticles after 3 and 6 months of storage at $4^{\circ} \mathrm{C}$ in their respective dilution media. As shown in Table 2, no significant changes in hydrodynamic diameter, PDI and $\zeta$-potential of the nanoparticles were found, indicating a good stability with time.

\section{Real-time cell analysis of nanoparticle cytotoxicity}

Endothelial cells are the first-contact vascular cells for any nanosystems designed for intravascular applications. A suitable in vitro method to investigate the potential toxicity of intravenously applied nanosystems is to test their effect on HUVECs, which serve as a model system of the human endothelium. Real-time cell analysis using xCELLigence is a well-established method used, among others, for nanotoxicity studies [33]. As described in detail in Online Supplement, cell index measured with this technique reflects cell viability, number, morphology and adhesion strength. To ensure that the tested nanoparticles do not interfere with the impedance measurements, a series of control experiments was performed. Importantly, the presence of nanoparticles alone (without cells) did not affect the impedance measured by the electrodes, as shown in Supplementary Figures 17-20. In studies with HUVECs, a steady increase in cell index was observed 
Table 1. Physicochemical characterization of nanoparticles.

\begin{tabular}{|c|c|c|c|c|}
\hline Nanoparticle type & Z-avg d(nm) & PDI & $\zeta(\mathrm{mV})$ & $\mathrm{SD} \zeta(\mathrm{mV})$ \\
\hline LD-NP1 & 53.3 & 0.156 & -7.0 & 14.5 \\
\hline LD-NP2 & 82.8 & 0.191 & -9.0 & 14.6 \\
\hline LD-NP3 & 120.1 & 0.151 & -8.8 & 8.4 \\
\hline LP-NP1 & 138.6 & 0.104 & -16.3 & 7.4 \\
\hline LP-NP2 & 108.8 & 0.034 & -9.0 & 4.7 \\
\hline PM-NP1 & 145.1 & 0.072 & -51.0 & 5.6 \\
\hline PM-NP2 & 226.9 & 0.194 & 3.3 & 5.7 \\
\hline IO-NP1 & 78.7 & 0.145 & -37.3 & 12.9 \\
\hline IO-NP2 & 79.6 & 0.173 & 13.7 & 9.3 \\
\hline IO-NP3 & 57.5 & 0.217 & -24.9 & 8.4 \\
\hline
\end{tabular}

over time in control (untreated) endothelial cells, but also in the cells treated with LP-NPs up to the highest tested concentration ( $400 \mu \mathrm{g} / \mathrm{ml}$, Figure 1). There were no significant differences in the growth curves of the liposome-treated cells versus control samples, showing a similar increase of cell index until the end of the measurement at $72 \mathrm{~h}$ post-application. In cells treated with $100 \mu \mathrm{g} / \mathrm{ml}$ LD-NP1 (Figure 2A), a decrease in cell index at 48 and $72 \mathrm{~h}$ was observed in comparison to control, indicative of cell growth inhibition or loss of adherence. Interestingly, the decrease in cell indices became obvious at the concentration of $100 \mu \mathrm{g} /$ $\mathrm{ml}$ for LD-NP1, $200 \mu \mathrm{g} / \mathrm{ml}$ for LD-NP2 and above $200 \mu \mathrm{g} / \mathrm{ml}$ for LD-NP3, suggesting that the larger lipid nanoparticles may be better tolerated by endothelial cells (Figure 2). For polymeric nanoparticles (Figure 3), the decrease in endothelial cell index rela- tive to the preapplication values, which was indicative of cytostatic or cytotoxic effects, was induced from the concentration of $50 \mu \mathrm{g} / \mathrm{ml}$ for PM-NP1, and from 100 $\mu \mathrm{g} / \mathrm{ml}$ for PM-NP2.

In cells treated with $50 \mu \mathrm{g} / \mathrm{ml} \mathrm{IO-NP1} \mathrm{(Figure} \mathrm{4),} \mathrm{a}$ significantly lower cell-index in comparison to control was observed at 48 and $72 \mathrm{~h}$, indicative of cell growth inhibition. The decrease in endothelial cell index relative to preapplication values, indicative of negative effects on cell viability or adherence was induced from the concentration of $100 \mu \mathrm{g} / \mathrm{ml} \mathrm{IO-NP1} \mathrm{(Figure} \mathrm{4A).}$ There were no significant differences in the growth curves of the cells treated with IO-NP2 versus control samples, showing a similar increase of cell index until the end of the measurement at $72 \mathrm{~h}$ post-application (Figure 4B). Since IO-NP3 were no longer stable upon dilution in the serum-containing endothelial cell

\begin{tabular}{|c|c|c|c|c|c|c|c|c|c|c|c|c|}
\hline \multirow[b]{2}{*}{$\begin{array}{l}\text { Nanoparticle } \\
\text { type }\end{array}$} & \multicolumn{4}{|c|}{1 month } & \multicolumn{4}{|c|}{3 months } & \multicolumn{4}{|c|}{6 months } \\
\hline & $\begin{array}{l}\text { Z-avg d } \\
(\mathrm{nm})\end{array}$ & PDI & $\zeta(\mathrm{mV})$ & $\begin{array}{l}\mathrm{SD} \zeta \\
(\mathrm{mV})\end{array}$ & $\begin{array}{l}\text { Z-avg d } \\
(\mathrm{nm})\end{array}$ & PDI & $\zeta(\mathrm{mV})$ & $\begin{array}{l}\mathrm{SD} \zeta \\
(\mathrm{mV})\end{array}$ & $\begin{array}{l}\text { Z-avg d } \\
(\mathrm{nm})\end{array}$ & PDI & $\zeta(\mathrm{mV})$ & $\begin{array}{l}\mathrm{SD} \zeta \\
(\mathrm{mV})\end{array}$ \\
\hline LD-NP1 & 53.3 & 0.156 & -7.0 & 14.5 & 52.5 & 0.142 & -8.5 & 11.5 & 53.3 & 0.193 & -7.7 & 4.6 \\
\hline LD-NP2 & 82.8 & 0.191 & -9.0 & 14.6 & 83.0 & 0.173 & -8.6 & 6.9 & 84.3 & 0.213 & -8.2 & 5.9 \\
\hline LD-NP3 & 120.1 & 0.151 & -8.8 & 8.4 & 125.7 & 0.161 & -9.0 & 7.3 & 123.5 & 0.156 & -8.4 & 5.3 \\
\hline LP-NP1 & 138.6 & 0.104 & -16.3 & 7.4 & 143.2 & 0.110 & -10.7 & 8.7 & 165.5 & 0.199 & -11.5 & 7.4 \\
\hline LP-NP2 & 108.8 & 0.034 & -9.0 & 4.7 & 108.6 & 0.016 & -7.4 & 9.7 & 107.6 & 0.040 & * & \\
\hline PM-NP1 & 145.1 & 0.072 & -51.0 & 5.6 & 135.7 & 0.087 & -53.4 & 8.4 & 139.1 & 0.108 & -47.6 & 10.1 \\
\hline PM-NP2 & 226.9 & 0.194 & 3.3 & 5.7 & 237.5 & 0.235 & 9.4 & 5.7 & 215.2 & 0.126 & 11.4 & 5.6 \\
\hline IO-NP1 & 78.7 & 0.145 & -37.3 & 12.9 & 84.4 & 0.258 & -44.3 & 11.6 & 71.1 & 0.160 & -43.4 & 10.7 \\
\hline IO-NP2 & 79.6 & 0.173 & 13.7 & 9.3 & 80.6 & 0.150 & -17.0 & 11.1 & 81.1 & 0.140 & -0.65 & 6.6 \\
\hline IO-NP3 & 57.5 & 0.217 & -24.9 & 8.4 & 68.9 & 0.252 & -35.0 & 9.6 & 58.8 & 0.228 & -26.6 & 7.2 \\
\hline
\end{tabular}


medium, yielding significant nanoparticle agglomeration at concentrations above $50 \mu \mathrm{g} / \mathrm{ml}$, the effect of IO-NP3 on HUVECs could not be investigated.

\section{Live cell imaging of nanoparticle-treated endothelial cells}

The results of real-time cell analysis were validated using live-cell microscopy. In contrast to real-time cell analysis, which estimates cell numbers, attachment and viability based on the impedance measurements, live-cell microscopy allows the observation of cell morphology, and the measurement of confluence at the same time (see also Supplementary Figures 21-24). Using this method, no differences were observed in confluence (Supplementary Figure 21) or morphology between untreated cells and the cells treated with different concentrations of LP-NPs, confirming the real-time analysis data (Figure $1 \mathrm{~A}-\mathrm{C}$ ). Upon treatment with LD-NP1, endothelial cell numbers were only slightly affected at $100 \mu \mathrm{g} / \mathrm{ml}$, but the morphology of the cells changed, starting at around $24 \mathrm{~h}$ of incubation, leading to an elongated phenotype at $28 \mathrm{~h}$ postapplication. At $200 \mu \mathrm{g} / \mathrm{ml}$, stronger cell elongation, and reduced number of adherent cells were observed at $24 \mathrm{~h}$ (Figure 2A, Supplementary Figure 22). For LD-NP2, slight morphological changes became apparent at $100 \mu \mathrm{g} / \mathrm{ml}$ after $30 \mathrm{~h}$ of incubation, which were more strongly pronounced at $200 \mu \mathrm{g} / \mathrm{ml}$, in parallel with reduced cell numbers after $48 \mathrm{~h}$ of incubation (Figure 2B). In LD-NP3-treated cells, reduced proliferation and strong elongation were detectable at $100 \mu \mathrm{g} /$ $\mathrm{ml}$ after $72 \mathrm{~h}$ and at $200 \mu \mathrm{g} / \mathrm{ml}$ after $48 \mathrm{~h}$ incubation (Figure 2C). Cytotoxicity was apparent for LD-NP2 at $400 \mu \mathrm{g} / \mathrm{ml}$ after $24 \mathrm{~h}$ incubation, for LD-NP3 at 400 $\mu \mathrm{g} / \mathrm{ml}$ after $48 \mathrm{~h}$ of incubation and for the smallest LD-NP1 at $200 \mu \mathrm{g} / \mathrm{ml}$ after $24 \mathrm{~h}$ of incubation.

Upon treatment with PM-NP1, strong reduction in cell number (reflected by decreased confluence, see Supplementary Figure 23) was visible at $50 \mu \mathrm{g} / \mathrm{ml}$, whereas the presence of dead cells was observed at 100 $\mu \mathrm{g} / \mathrm{ml}$ (Figure 3A). Treatment with $50 \mu \mathrm{g} / \mathrm{ml}$ PM-NP2 did not significantly affect cell numbers or morphology. Cytotoxic effects were observable from $100 \mu \mathrm{g} /$ $\mathrm{ml}$ (Figure 3B). In the case of iron oxide nanoparticles, decreased cell numbers were observed upon treatment

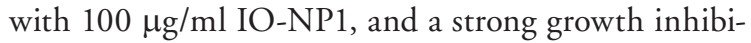
tion accompanied by cell shape change was induced at $200 \mu \mathrm{g} / \mathrm{ml}$ (Figure 4A, Supplementary Figure 24). In contrast, up to $400 \mu \mathrm{g} / \mathrm{ml}$ of IO-NP2 were well tolerated by endothelial cells and did not affect the morphology or confluence of cells as compared with untreated controls (Figure 4B).

Taken together, the results of real-time cell analysis and live-cell microscopy indicated that for the major- ity of the tested nanosystems, there were no significant toxic effects on HUVECs up to the concentration of $100 \mu \mathrm{g} / \mathrm{ml}$. Because of the biological/cytotoxic effects observed at and above $100 \mu \mathrm{g} / \mathrm{ml}$ for LD-NPs, PM-NPs and IO-NPs, subsequent studies under flow conditions were performed to investigate the effects of circulating nanosystems in physiological-like settings.

\section{Nanoparticle effects on ECs in dynamic cell culture conditions}

In physiological conditions, endothelial cells are constantly exposed to shear stress induced by the flow of blood and its viscosity, and their responses to stimuli are determined by the patterns of shear stress. Whereas laminar flow protects endothelial cells from harmful stimuli, nonuniform shear stress induces endothelial activation [31]. Furthermore, recent studies showed that the endothelial uptake on untargeted nanoparticles greatly depends on the presence and magnitude of shear stress [34-36]. Therefore, experiments under flow conditions are necessary to estimate the cell responses in physiological-like settings. In vitro, the toxic effects of circulating substances manifest themselves as endothelial cell shrinking and detachment. Consequently, the viability and confluence of the cells upon treatment with nanoparticles, as well as their morphology and cell-cell contacts can be assessed by immunofluorescent staining. We therefore perfused a HUVEC monolayer with medium containing 100 or $400 \mu \mathrm{g} / \mathrm{ml}$ of nanoparticles for $18 \mathrm{~h}$ and subsequently compared the nanoparticle effects on cells exposed to different types of shear stress (laminar vs non-uniform shear stress). In contrast to static conditions, all LD-NPs (Figure 5) and IO-NP1 (Figure 6) were well tolerated by the cells up to $400 \mu \mathrm{g} / \mathrm{ml}$ and did not affect endothelial cell viability and morphology, nor induced cell detachment due to shear stress exposure. In the case of PM-NP1, the circulating nanoparticles induced endothelial cell rounding at $100 \mu \mathrm{g} / \mathrm{ml}$, and resulted in massive cell detachment both in the laminar and nonuniform shear stress region at $400 \mu \mathrm{g} / \mathrm{ml}$ (Figure 6A). The negative effects of circulating PM-NP2 on HUVECs remained observable at $100 \mu \mathrm{g} / \mathrm{ml}$ (Figure 6B), similar as seen in static conditions.

\section{Reaction to liposomal nanoparticles in a pig model of CARPA}

Evaluation of cardiovascular changes upon intravenous bolus injection of LP-NP1 at two different doses (0.1 and $0.5 \mathrm{mg}$ phospholipid $/ \mathrm{kg}$ ) was done in domestic pigs. After the negative control injection ( 5 $\mathrm{ml}$ saline), the first test dose ( $0.1 \mathrm{mg}$ phospholipid $/ \mathrm{kg}$ ) was diluted in $5 \mathrm{ml}$ of sterile PBS and injected as a 
(A)

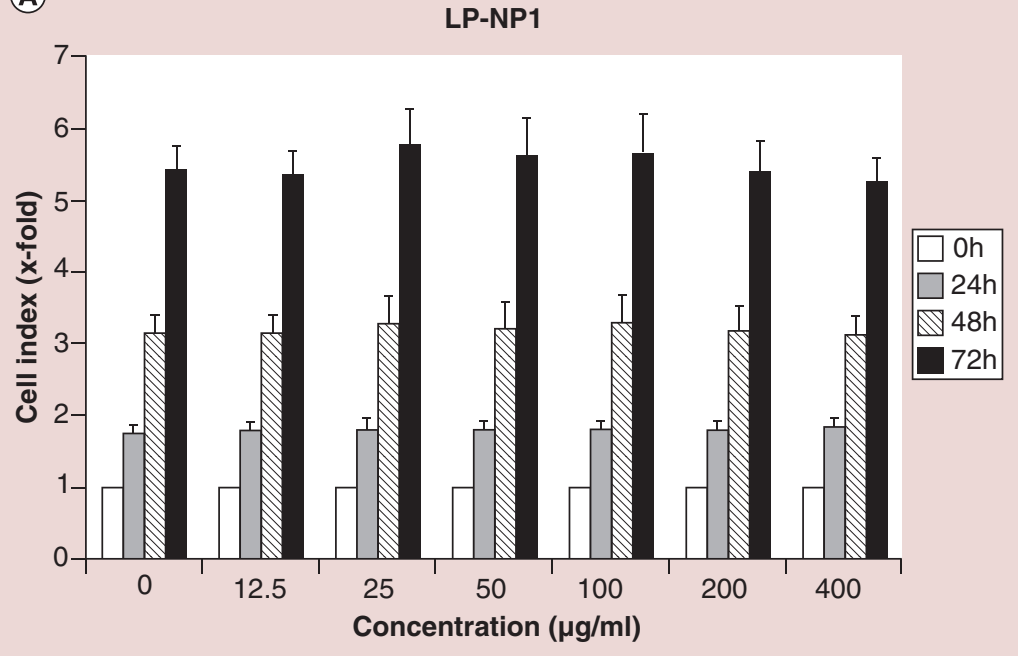

(B)

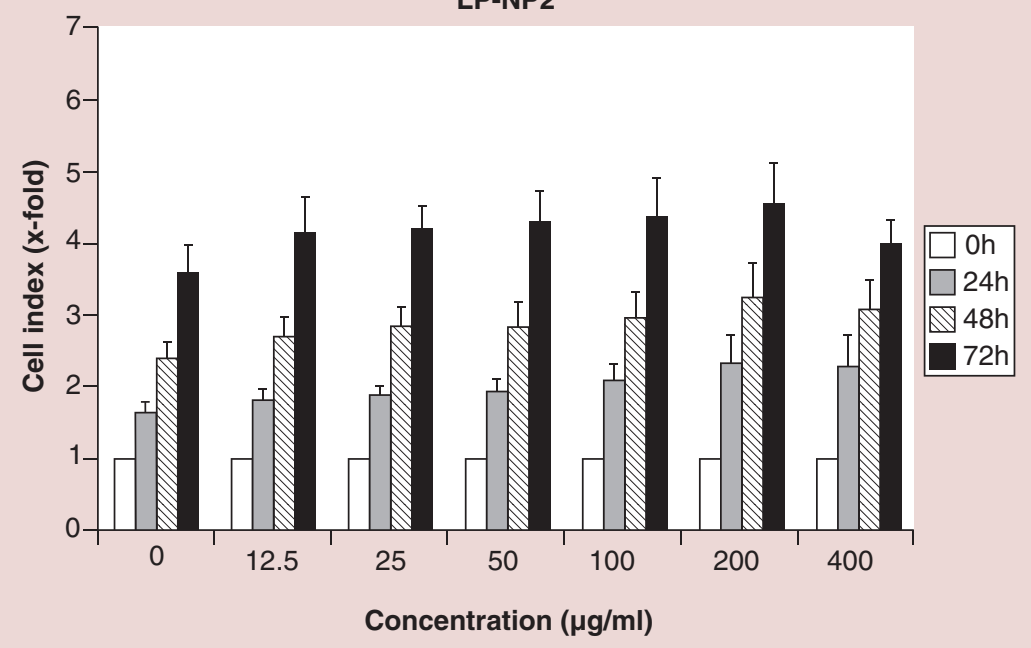

LP-NP1

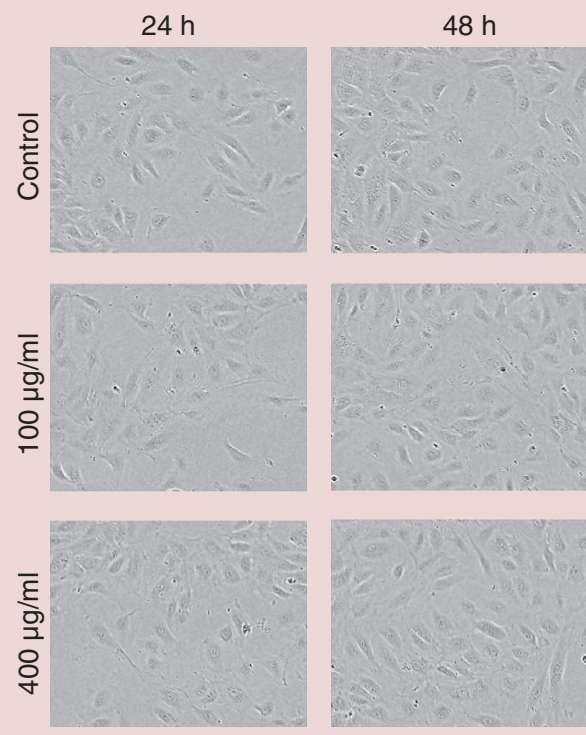

LP-NP2


Figure 1. Biological effects of liposomes on endothelial cells grown in static conditions. HUVECs were treated with (A) LP-NP1 and (B) LP-NP2 for up to $72 \mathrm{~h}$. Left panel: Real-time cell analysis. Cell index is displayed as x-fold of untreated controls. Right panel: Live-cell microscopy images at $\times 10$ objective magnification. Data are expressed as mean \pm SEM.

${ }^{*} \mathrm{p}<0.05,{ }^{* *} \mathrm{p}<0.01, * * * \mathrm{p}<0.001$ vs control (one-way ANOVA); $\mathrm{n}=4$.

bolus in the external jugular vein of anesthetized ani- The steady increase of HR was not nanoparticle-related. mal (see online supplement for the outline of the pig model). The saline injection caused no cardiovascular changes. Following the injection of LP-NP1 at $0.1 \mathrm{mg} /$ $\mathrm{kg}$ dose, mild PAP increase was observed (from 16.6 to $20.9 \mathrm{mmHg}$ ), without any other changes (Figure 7A).

To test for the presence of tachyphylaxis (desensitization), the same dose was repeatedly injected $30 \mathrm{~min}$ later. This repeated $0.1 \mathrm{mg} / \mathrm{kg}$ bolus injection caused no reaction, just like the subsequent injection of $5 x$ higher dose $(0.5 \mathrm{mg} / \mathrm{kg}$ LP-NP1), indicating that there

Figure 2. See facing page. Biological effects of lipid nanoparticles on endothelial cells grown in static conditions. HUVECs were treated with (A) LD-NP1, (B) LD-NP2 and (C) LD-NP3 for up to $72 \mathrm{~h}$. Left panel: Real-time cell analysis. Cell index is displayed as x-fold of untreated controls. Right panel: Live-cell microscopy images at $\times 10$ objective magnification. Data are expressed as mean \pm SEM. ${ }^{*} \mathrm{p}<0.05, * * \mathrm{p}<0.01, * * * \mathrm{p}<0.001$ vs control (one-way ANOVA); $\mathrm{n}=3$ 
(A)

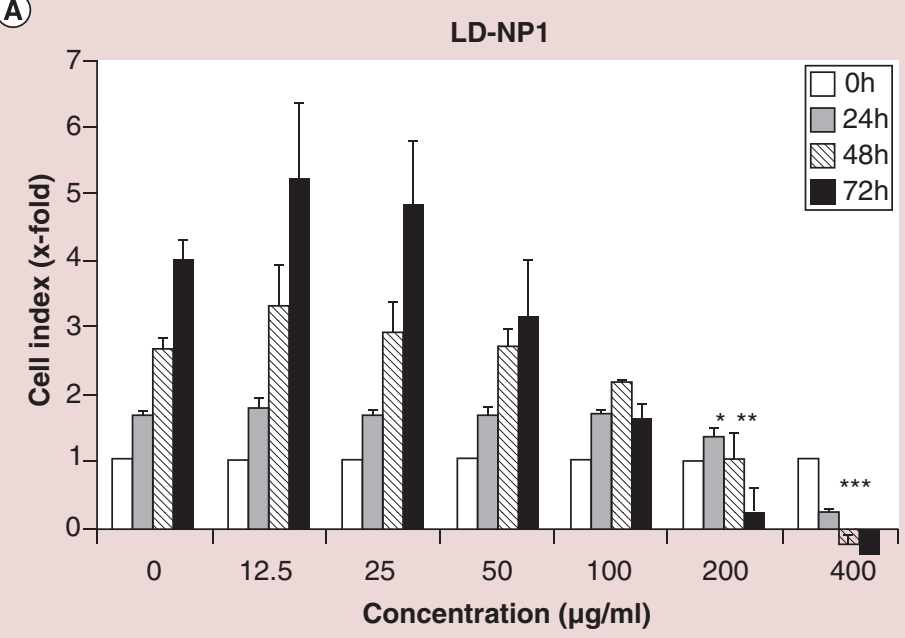

(B)

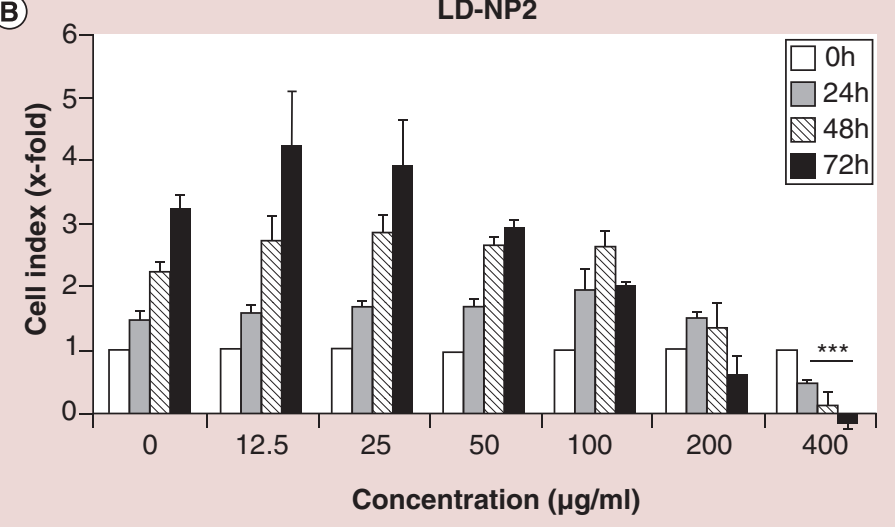

(C)

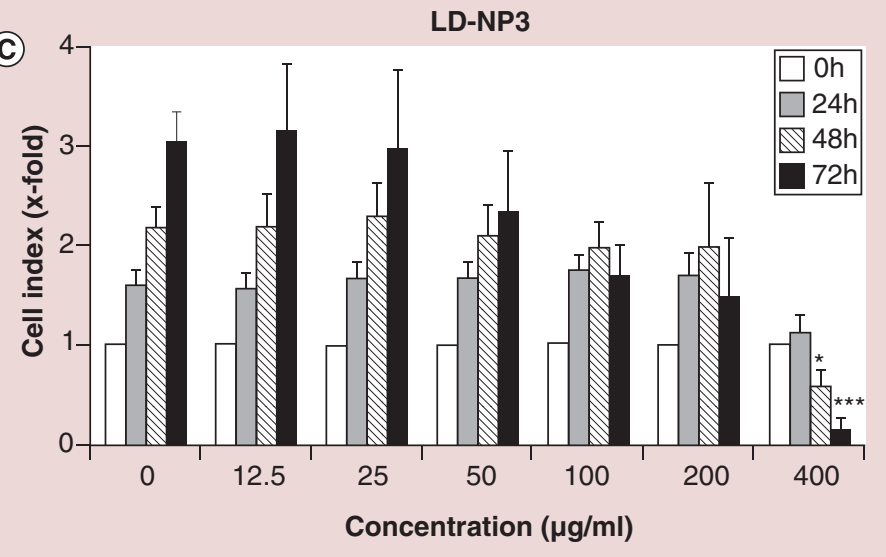

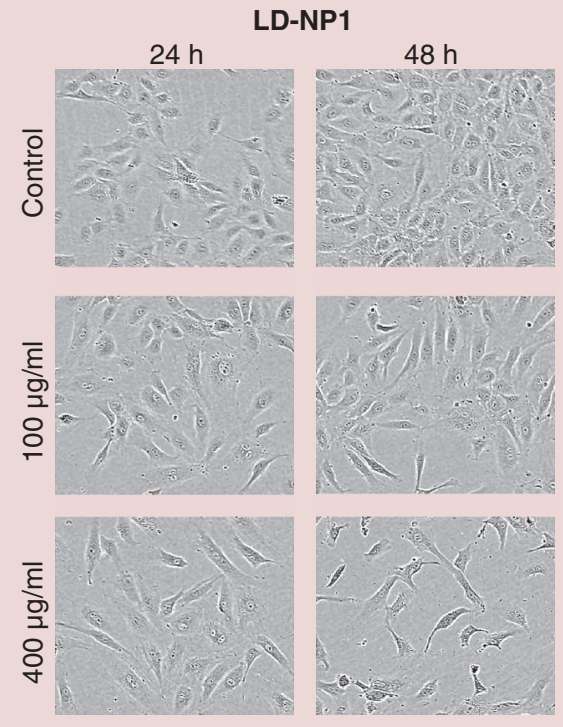
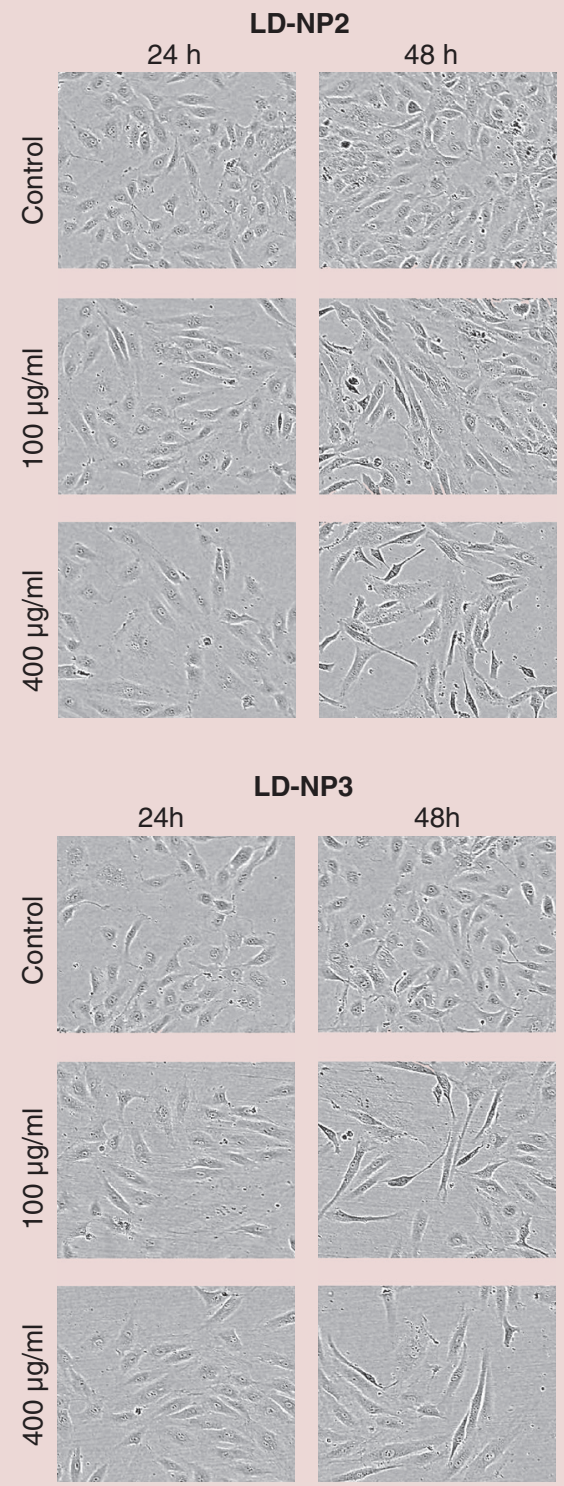


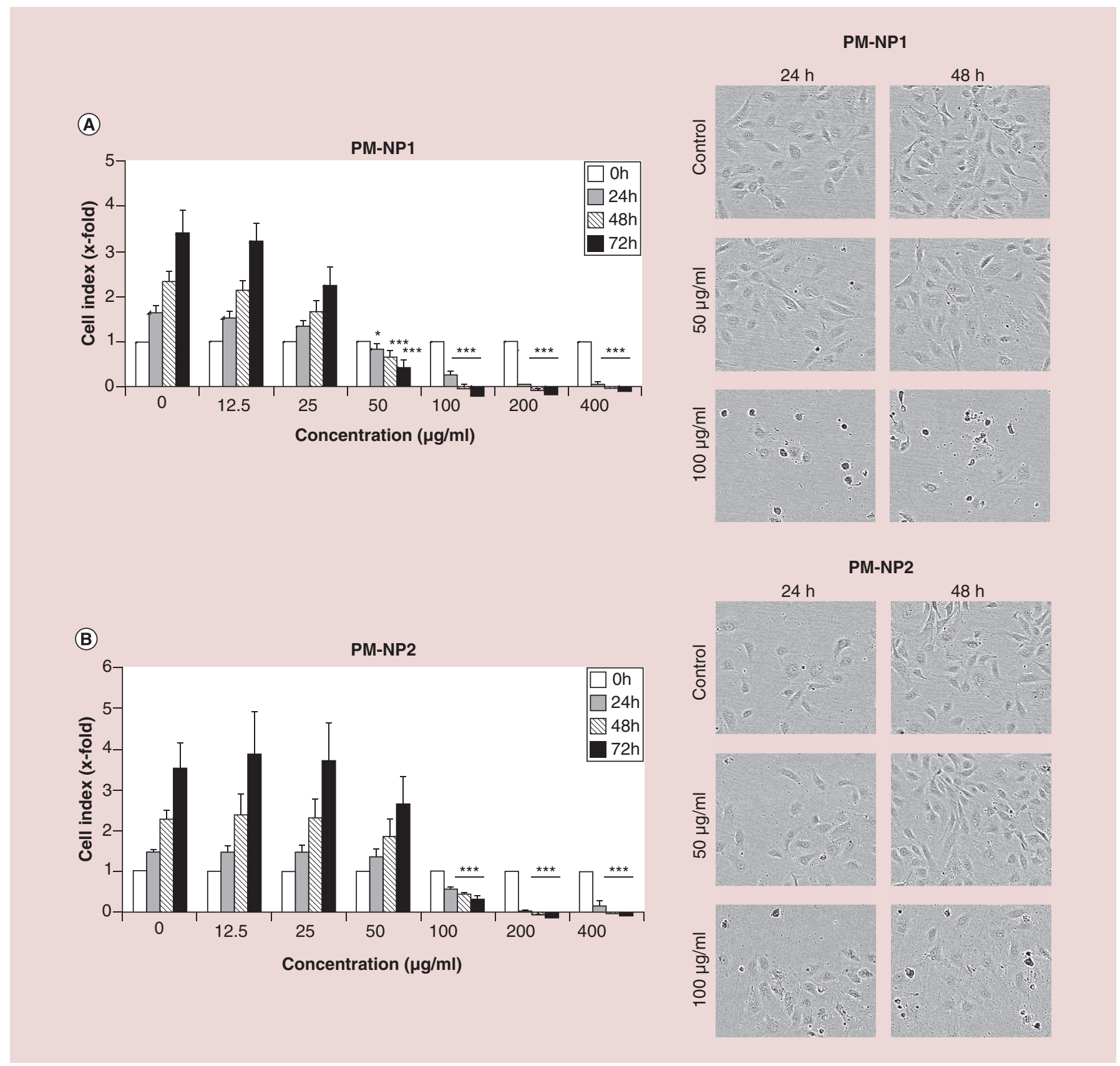

Figure 3. Biological effects of polymeric nanoparticles on endothelial cells grown in static conditions. HUVECs were treated with (A) PM-NP1 and (B) PM-NP2 for up to $72 \mathrm{~h}$. Left panel: Real-time cell analysis. Cell index is displayed as $\mathrm{x}$-fold of untreated controls. Right panel: Live-cell microscopy images at $\times 10$ objective magnification. Data are expressed as mean \pm SEM.

${ }^{*} \mathrm{p}<0.05,{ }^{* *} \mathrm{p}<0.01,{ }^{* *} \mathrm{p}<0.001$ vs control (one-way ANOVA) $\mathrm{n}=5$ for PM-NP1; $\mathrm{n}=3$ for PM-NP2.

was full tachyphylaxis. The positive control, zymosan at $0.1 \mathrm{mg} / \mathrm{kg}$ evoked severe PAP increase and a short lasting SAP decrease. The most characteristic PAP changes during the three LP-NP1 and zymosan injections, expressed as the $\%$ of the preinjection values, are shown in Figure 7B.

Pulmonary hypertension is closely associated with elevations of plasma thromboxane in response to zymo- san-induced complement activation [37,38]. TXB2 measurement in blood samples collected before injections and during the reactions showed an approximate $40 \%$ TXB2 elevation in the later phase $(10 \mathrm{~min})$ following the first $0.1 \mathrm{mg} / \mathrm{kg}$ LP-NP1 injection (Figure 7C). Upon repeated injection, the same dose caused neither PAP nor TXB2 elevation (not shown), which confirmed the presence of tachyphylaxis. 


\section{Discussion}

Detailed in vitro characterization facilitates the prediction of nanoparticle behavior in more complex physiological conditions, and is a prerequisite for human use [39]. We therefore investigated 10 nanoparticle systems, including lipid nanoparticles (Lipidots), liposomes, polymeric nanoparticles and iron oxide nanoparticles with regard to their physicochemical features, stability and biological effects. Important parameters affecting nanoparticle properties include size, charge and PDI [40]. Size is one of the critical factors that affect the circulation time and bioavailability of nanoparticles. Surface charge, indicated by the $\zeta$-potential, has a strong influence on nanoparticle sta-

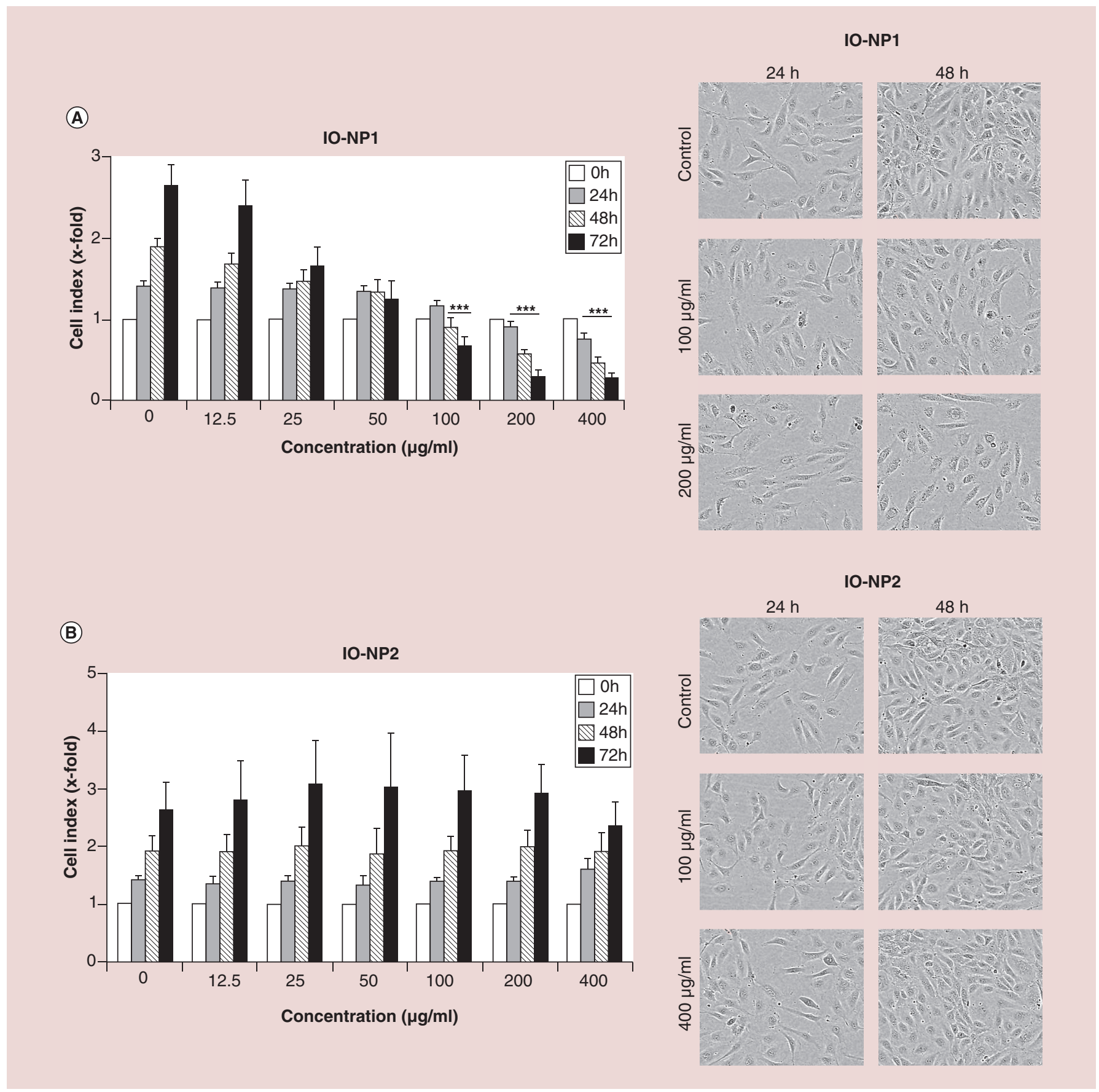

Figure 4. Biological effects of iron oxide nanoparticles on endothelial cells grown in static conditions. HUVECs were treated with (A) IO-NP1 and (B) IO-NP2 for up to $72 \mathrm{~h}$. Left panel: Real-time cell analysis. Cell index is displayed as x-fold of untreated controls. Right panel: Live-cell microscopy images at $\times 10$ objective magnification. Data are expressed as mean $\pm \mathrm{SEM}$.

${ }^{*} \mathrm{p}<0.05,{ }^{* *} \mathrm{p}<0.01,{ }^{* *} \mathrm{p}<0.001$ vs control (one-way ANOVA) $\mathrm{n}=6$ for IO-NP1; $\mathrm{n}=3$ for IO-NP2. 


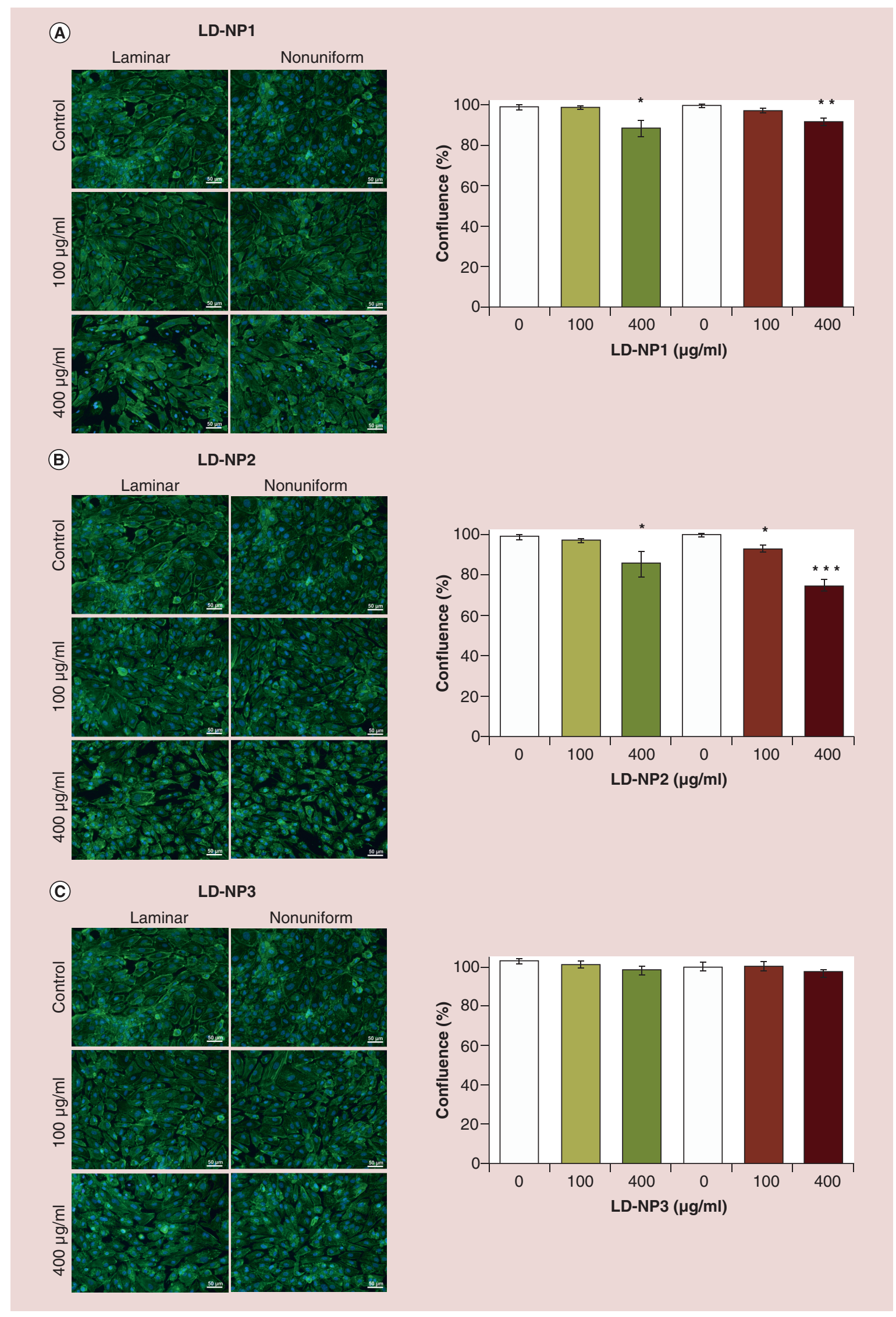


Figure 5. See facing page. Biological effects of circulating lipid nanoparticles on endothelial cells grown under flow conditions. HUVECs were grown in bifurcating slides until confluence and perfused for $18 \mathrm{~h}$ with medium containing LD-NP1 (A), LD-NP2 (B), or LD-NP3 (C) at 100 and $400 \mu \mathrm{g} / \mathrm{ml}$. Left panel: Fluorescent images of representative laminar and nonuniform regions at $20 \times$ objective magnification are shown. F-actin was visualized with Alexa 488-conjugated 488 (green) and nucleus with Hoechst 33342 (blue). Right panel: The graphs show a semiquantitative analysis of the confluence in laminar (green bars) and nonuniform region (red bars), determined on $\times 10$ objective magnification images using ImageJ software. Nanoparticle-untreated controls (white columns) were set to $100 \%$. Data are expressed as mean \pm SEM.

${ }^{*} \mathrm{p}<0.05,{ }^{* *} \mathrm{p}<0.01,{ }^{* * *} \mathrm{p}<0.001$ vs corresponding control.

bility in biological fluids. Moreover, positively charged nanoparticles enhance cellular uptake and can induce cytotoxicity $[40,41]$. Nanoparticles with a $\zeta$-potential above (+/-) $30 \mathrm{mV}$ are usually considered as colloidally stable, since the surface charge prevents their aggregation, but $\zeta$-potential cannot be regarded as an absolute predictor of nanoparticle stability, especially in biological fluids as the $\zeta$-potential is dependent on solvent composition. Steric repulsion, such as the hindrance provided by a PEGylated coating of the nanoparticle surface, can also provide high colloidal stability despite a nearly neutral $\zeta$-potential [42].

Nanoparticle agglomeration is thus influenced by their physicochemical properties, but also by extrinsic factors, for example, temperature, as well as $\mathrm{pH}$, osmotic strength and the presence of serum in the dispersion media. For clinical applications, nanoparticle agglomeration may be a key factor limiting their use in patients, as it affects bioavailability, and thus efficacy. Aggregated nanoparticles are no longer nanosized, and undergo a rapid recognition by the reticuloendothelial system followed by the clearance via liver or spleen. Moreover, the presence of agglomerates in circulation may cause serious undesirable side effects, such as clogging blood or lymphatic vessels [41]. In our study, although the results of physicochemical characterization of all investigated nanosystems in their respective dilution media indicated a good colloidal stability also upon prolonged storage, one type of nanoparticles (IO-NP3) was prone to agglomeration in serum-containing media, and was therefore excluded from biocompatibility testing. This underlines that only a careful nanoparticle analysis enables the design of a stable, clinically safe nanosystem.

The potential toxicity of nanoparticles is a major concern that must be excluded prior to their application in humans [39]. As nanoparticles may interfere with the available photometric methods for testing cell viability and/or metabolic activity [26,43-44], it is important to use in parallel at least two different methods for toxicity testing, to enable the verification of the results. In our studies, the biological effects of nanoparticles on endothelial cells were analysed in vitro using two real-time cell-monitoring methods. The obtained data underscore the importance of applying different methods to assess the toxicity of nanoparticles, as one single method may increase the risk of bias. For example, the impedance measurements indicated a negative effect of LD-NP1 at $100 \mu \mathrm{g} / \mathrm{ml}$ on HUVECs (cell-index significantly lower in comparison to control), hinting to a reduced endothelial cell numbers, whereas the results of live-cell microscopy indicated a change in cell morphology, possibly resulting in weaker adherence of the cells, that is responsible for the measured impedance differences. Smaller lipid nanoparticles (LD-NP1) had more pronounced effect on cell elongation and adherence of the cells than larger lipid nanoparticles. This could be due both to the effect of higher surfactant concentration and the small size facilitating the uptake. Concerning the mechanisms of nanoparticleinduced toxicity, we did not observe acute cell death accompanied by the rupture of plasma membrane, which would be indicative of necrosis. Based on the morphological features, including blebbing and cell shrinkage occurring over longer incubation periods, most probably the apoptotic processes were responsible for cell death induced at the concentrations of, and above, $100 \mu \mathrm{g} / \mathrm{ml}$ of the tested nanoparticles. To gain a more detailed insight into the mechanisms of toxicity, future studies including annexin $V$ and caspases staining would be necessary.

Compared with iron oxide nanoparticles, which have been extensively investigated for their effects on endothelial cells, very scarce information are available regarding the endothelial toxicity of solid lipid nanoparticles or polymeric nanoparticles composed of PIBCA. Lipid particles composed of cetyl palmitate and polysorbate 80 have been well tolerated by human cerebral microvascular endothelial cell line up to 1500

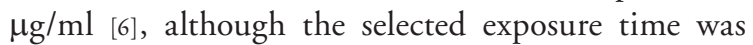
very short $(4 \mathrm{~h})$. Polymeric nanoparticles coated with fucoidan and dextran have previously been tested by Lira et al. [45] on macrophage and fibroblast cell lines, showing the $\mathrm{IC}_{50}$ of $9.6 \mu \mathrm{g} / \mathrm{ml}$ after $48 \mathrm{~h}$ incubation, but no data are available in the literature concerning their endothelial effects. Stealth liposomes of various compositions are generally well tolerated by endothelial cells $[46,47]$, which is in agreements with our present observations. The largest pool of data related to endothelial toxicity is thus far available for iron oxide nanoparticles (reviewed in $[48,49]$ ). Based on the existing literature, the presence and the type of coating is a 
(A)
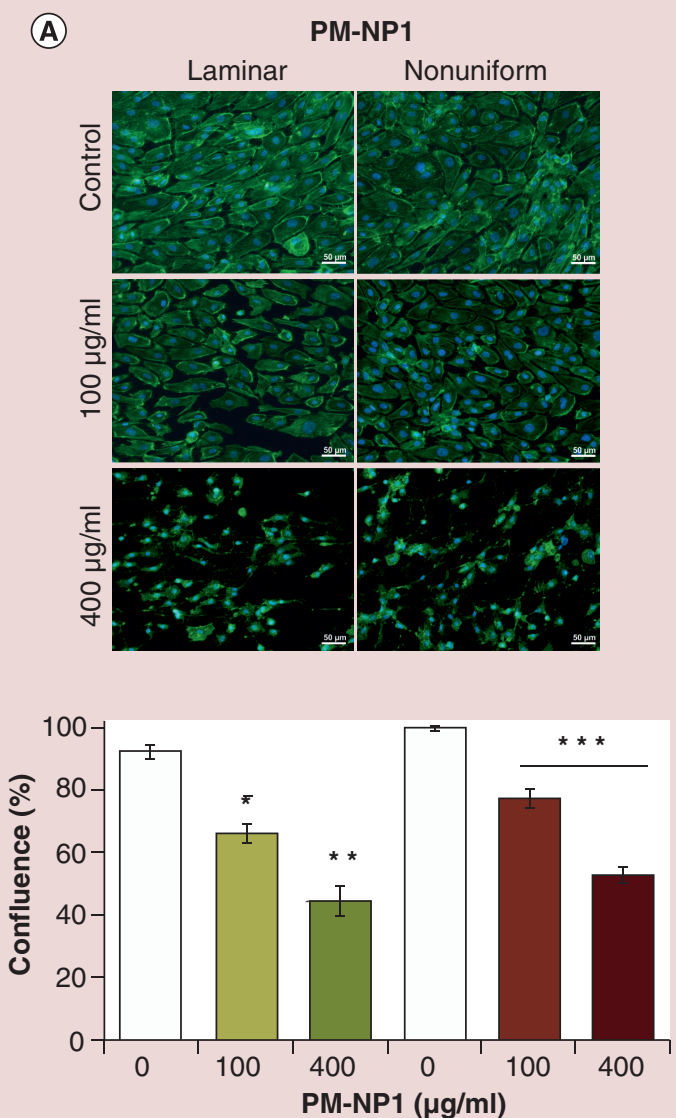

(C)
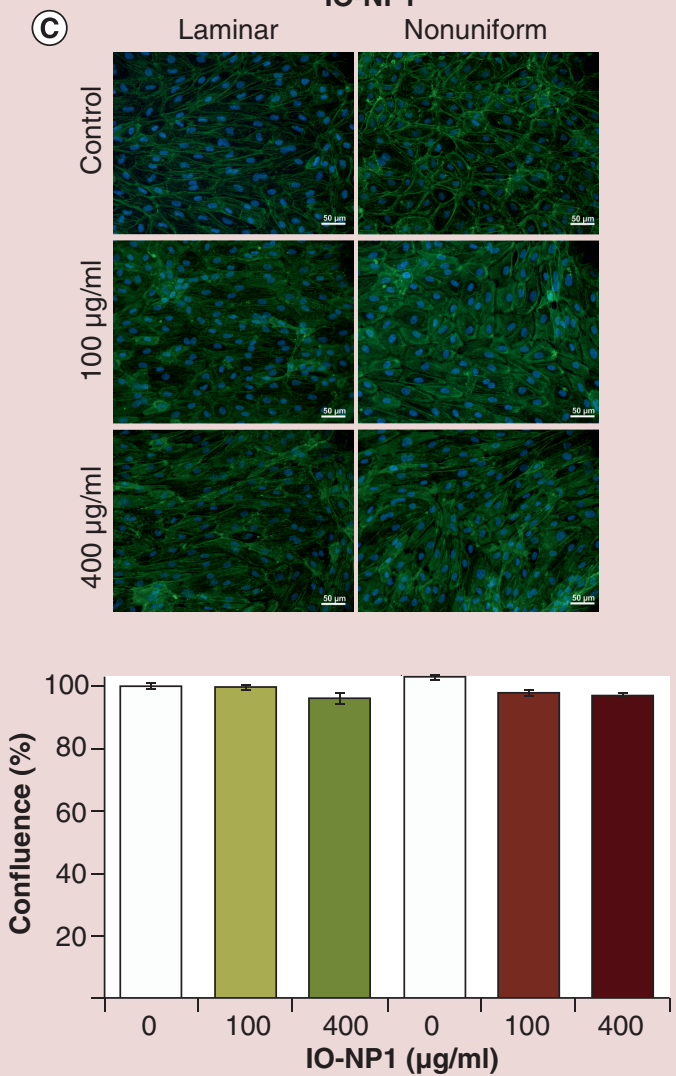

(B)

PM-NP2
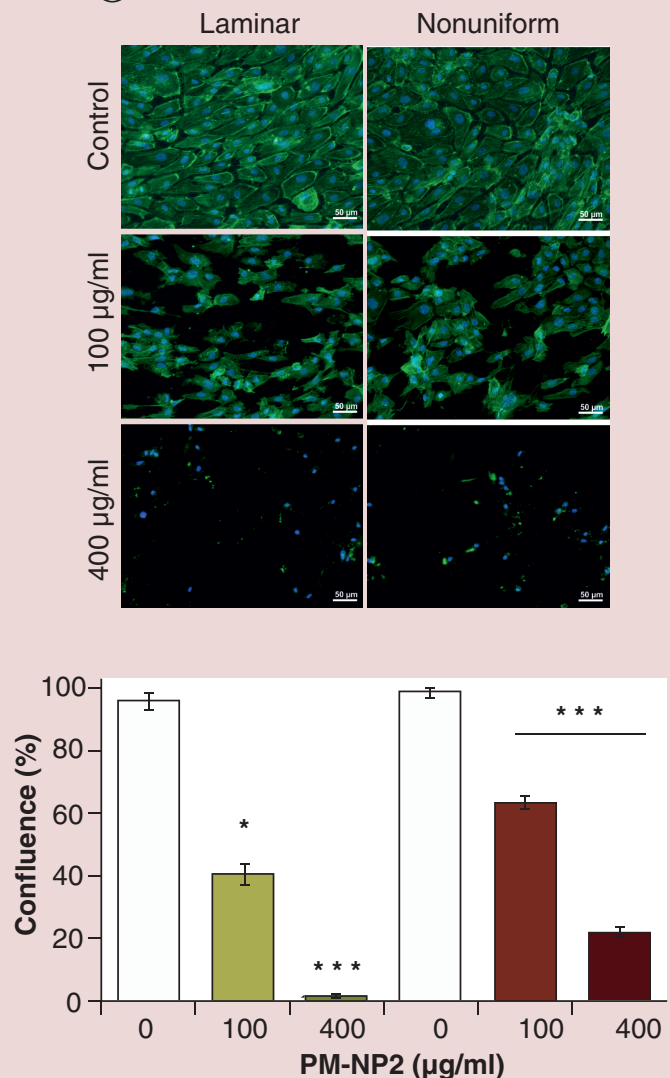

IO-NP2

(D) Laminar Nonuniform
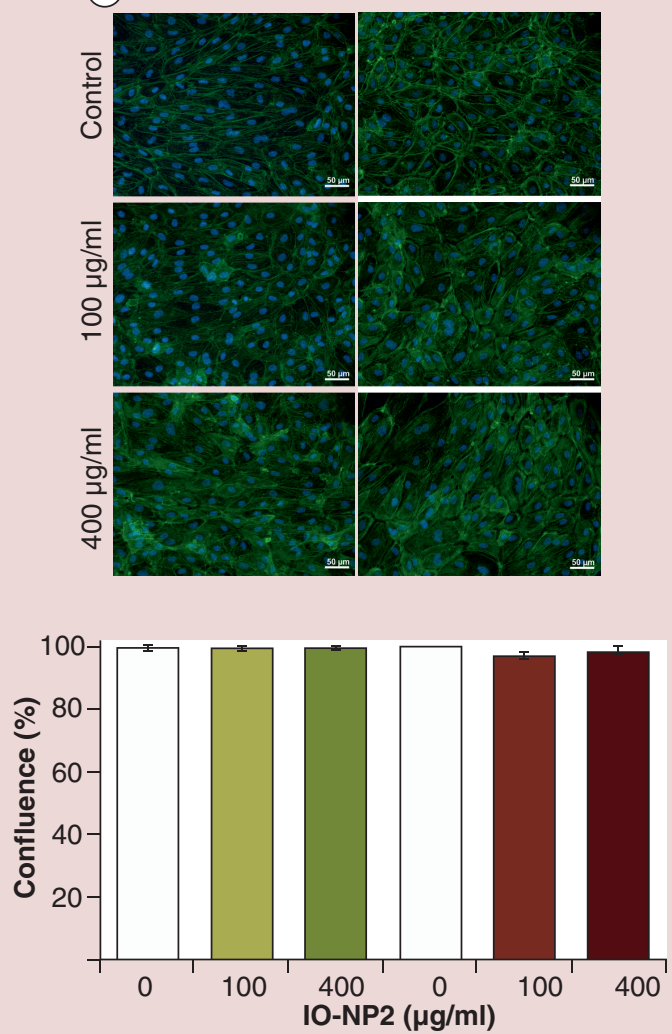
Figure 6. See facing page. Biological effects of circulating PM-NPs and IO-NPs on endothelial cells grown under flow conditions. HUVECs were grown in bifurcating slides until confluence and perfused for $18 \mathrm{~h}$ with medium containing PM-NP1 (A), PM-NP2 (B), IO-NP1 (C), or IO-NP2 (D) at 100 and $400 \mu \mathrm{g} / \mathrm{ml}$. Upper panel: Fluorescent images of representative laminar and nonuniform regions at $20 \times$ objective magnification are shown. F-actin was visualized with Alexa 488-conjugated 488 (green) and nucleus with Hoechst 33342 (blue). Lower panel: The graphs show a semiquantitative analysis of the confluence in laminar (green bars) and nonuniform region (red bars), determined on $\times 10$ objective magnification images using ImageJ software. Nanoparticle-untreated controls (white columns) were set to $100 \%$. Data are expressed as mean \pm SEM.

${ }^{*} p<0.05, * * p<0.01, * * * p<0.001$ vs corresponding control.

decisive factor for the biocompatibility of these particles [50,51], with good endothelial compatibility of dextran- and PEG-coated iron oxide nanoparticles up to $500 \mu \mathrm{g} / \mathrm{ml}$ over $24 \mathrm{~h}$, as reported by Yu et al. [50]. The net effect of iron oxide nanoparticles was also related to the amount of cellular uptake, which differs strongly among different formulations [51,52]. These data are in accordance with our observations, indicating very good biocompatibility of dextran-coated IO-NP2 at all tested concentrations, and little endothelial toxicity of lauric acid/albumin-coated IO-NP1 below $100 \mu \mathrm{g} / \mathrm{ml}$.

It must be noted that the nanoparticle toxicity was tested up to a very high concentration $(400 \mu \mathrm{g} / \mathrm{ml})$. Such high doses (above $100 \mu \mathrm{g} / \mathrm{ml}$ ) are not expected to occur in the systemic circulation in vivo, but may be encountered locally at the region of administration and should therefore be considered in analyses. Caution is also necessary when interpreting the results obtained with iron oxide nanoparticles versus other nanoparticle types, as the concentrations of the former are normalized to the total iron content, which corresponds to a much higher total dry mass weight. We have applied long-term monitoring techniques instead of singlepoint measurements, to ensure the toxicity readouts over extended time. Although some nanoparticles, particularly those intended for imaging applications will be expected to circulate for relatively short time, thus far no detailed pharmacokinetics and clearance data are available. Hence, the long-term effects must be investigated both for intended imaging and therapeutic nanosystems to ensure their safety also over extended periods of time.

In endothelial cells, constantly exposed to the blood flow, shear stress-activated mechanisms are one of the major modulators of the physiologic functions, but little is known about the influence of hemodynamic factors on the endothelial responses to circulating nanoparticles. In vitro assays in dynamic conditions corresponding to the physiological environment of endothelial cells are thus of critical importance, as the susceptibility to atherosclerosis is governed by the specific patterns of shear stress. In general, our data indicate that in case of nanoparticles, the cell culture assays under static conditions may overestimate the potential toxicity. This results from the inherent prop- erty of nanoparticles, namely their sedimentation, which occurs over time and leads to increased effective concentrations of nanoparticles in the nearest vicinity of cell monolayer. As shown in our studies, this effect is responsible for the majority of the cytostatic and cytotoxic effects observed below the concentration of $200 \mu \mathrm{g} / \mathrm{ml}$. Only for one nanoparticle type (PM-NP2), the concentrations affecting cell growth and viability in static conditions $(100 \mu \mathrm{g} / \mathrm{ml})$ also induced cell detachment under flow conditions, other nanosystems being well-tolerated under flow up to $400 \mu \mathrm{g} / \mathrm{ml}$. This may be related to the fact that except IO-NP2, PM-NP2 are the only positively charged nanoparticles, characterized furthermore by a relatively large $\mathrm{Z}$-average size and a tendency to aggregate. Collectively, these features may negatively affect endothelial cell growth and viability at concentrations of $100 \mu \mathrm{g} / \mathrm{ml}$ and higher. Moreover, the recently reported data as well as our present studies indicate that physiologic flow is one of the important factors that must be considered when designing drug delivery nanosystems, as the internalization of untargeted nanoparticles by endothelial cells differs greatly between static and dynamic conditions [34-36].

Due to their size, nanoparticles may remain in the circulation for several hours or more, and their in vivo behavior and interactions with cellular and extracellular substrates may induce undesired effects, including hemolytic reactions, and/or complement activation. Apart from clinical efficacy and safety, diagnostic and therapeutic nanosystems should therefore offer the possibility of repeated intravenous/intra-arterial administration without inducing anaphylactoid (hypersensitivity) reactions. In this context, the clinical significance of CARPA-genic reaction upon the intravenous administration of nanosystems lies not only in the severe, occasionally lethal cardiopulmonary distress but also in a heightened risk that the nanomedicines become immunogenic, preventing their multiple applications [32]. In order to minimize such risks, the nanoparticles included in our analyses are currently entering the CARPA tests in the pig model [53]. The results of a pilot study involving the intravenous bolus administration of LP-NP1 confirmed the in vitro data, indicating a favorable safety profile and low immunogenicity of these nanoparticles. In the next stage of the 


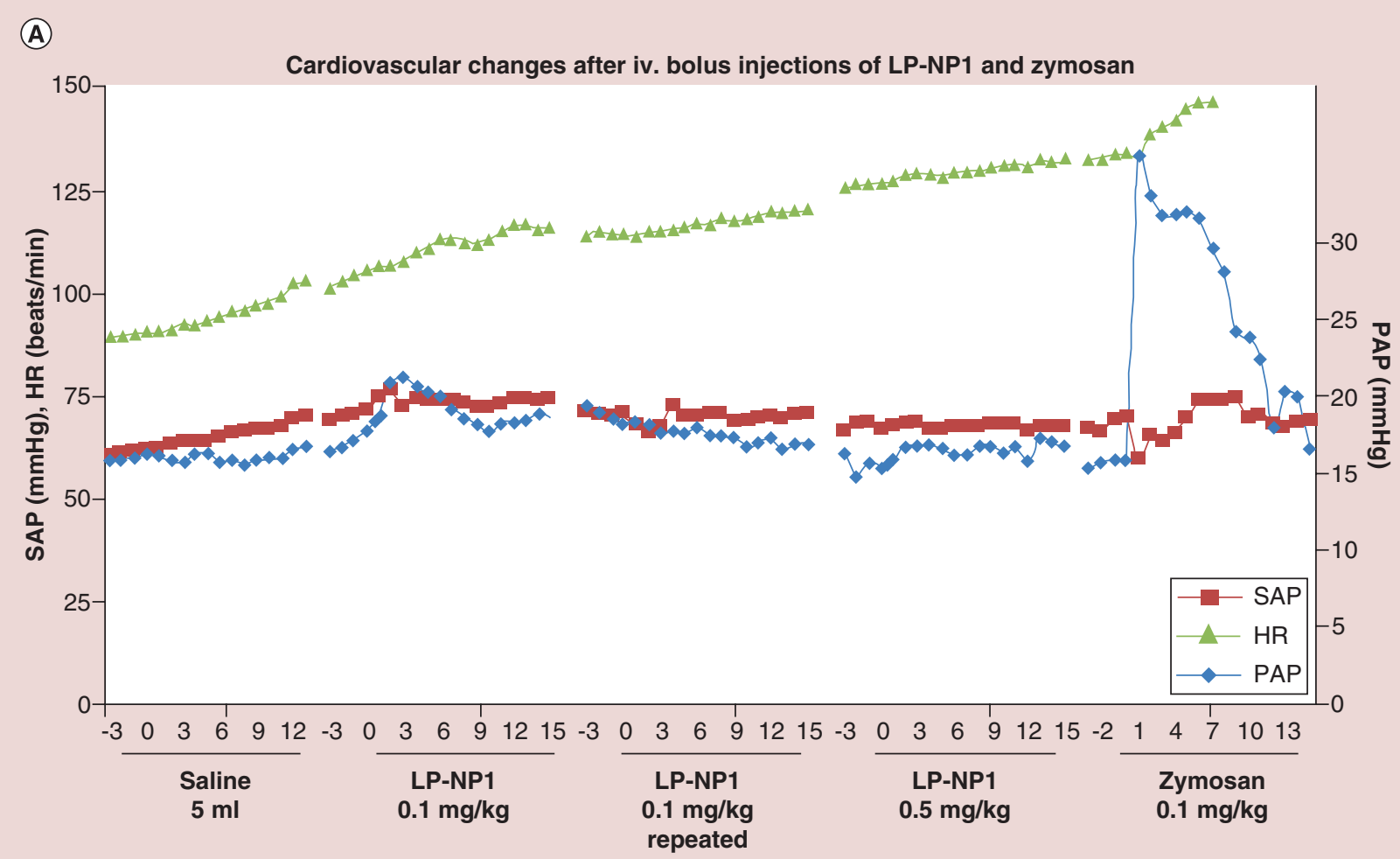

(B)

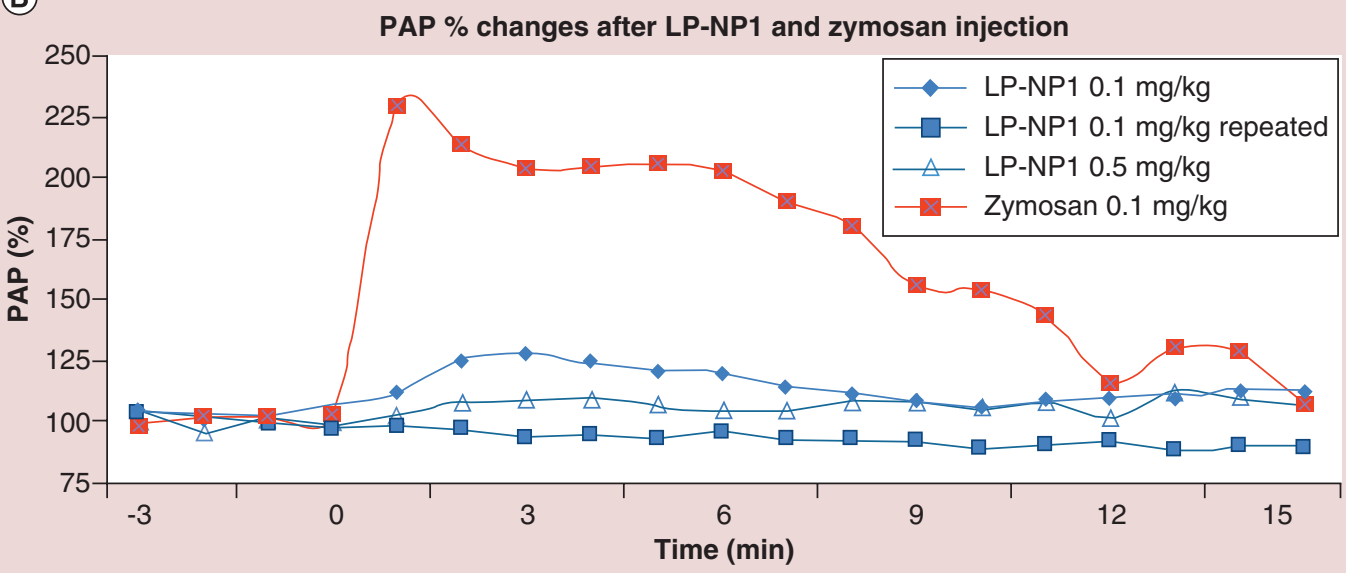

(C)

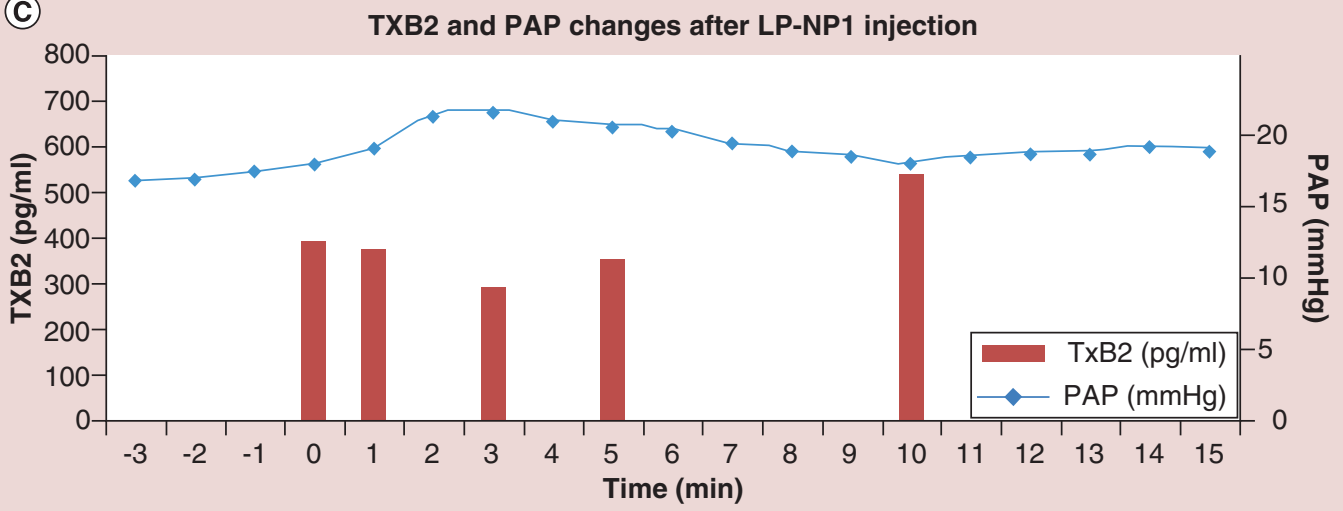


Figure 7. Cardiovascular reaction to LP-NP1 in a pig model of CARPA. LP-NP1 $(0.1 \mathrm{mg} / \mathrm{kg}$ or $0.5 \mathrm{mg} / \mathrm{kg})$ were administered intravenously as a bolus injection. Saline and zymosan $(0.1 \mathrm{mg} / \mathrm{kg})$ were used as negative and positive controls, respectively. (A) Changes in SAP, HR and PAP upon iv. injection of NP-LP1. (B) Percentage changes in PAP after LP-NP1 injection. (C) Plasma concentrations of TXB2 in relation to PAP changes following LP-NP1 injection are shown.

project, in vivo tests of other nanosystems selected for further development, as well as the determination of pharmacokinetics will be performed.

\section{Conclusion}

In this study we report the results of systematic physicochemical and biological analysis of diverse nanosystems intended for intravascular applications. The majority of nanosystems were well tolerated by endothelial cells, and did not induce major toxic effects in vitro up to the concentration of $100 \mu \mathrm{g} / \mathrm{ml}$ in static, and up to $400 \mu \mathrm{g} / \mathrm{ml}$ in dynamic cell culture conditions. These findings indicate an overall favorable biocompatibility profile of the tested nanosystems and their potential for cardiovascular imaging and drug targeting applications.

\section{Future perspective}

The potential clinical impact of nanotechnology in terms of detection and management of cardiovascular diseases is enormous. But in spite of the promising results obtained in the vast number of bench investigations that have been published in the recent years [4], no specific nanoparticle-based system has been approved for diagnosis or therapy of atherosclerosis in humans. The reasons for that are mainly the safety requirements related to nanoparticulate medicines, the lacking regulatory guidelines and insufficient standardization in the matters of particle characterization and nanotoxicity testing. To ensure clinical safety, the intravascular diagnostic and drug-delivery systems must first be subject to a close toxicologic scrutiny in vitro. Our studies represent an attempt to advance this field by utilizing a systematic approach to the comparative analysis of nanoparticle effects on primary human endothelial cells. Importantly, no interference resulting from the presence nanoparticles was observed in real-time cell analysis method, indicating the suitability of this technique for the future nanotoxicology studies. Furthermore, the comparison of nanoparticle effects on cell viability in static culture conditions and the effects of circulating nanoparticles on endothelial monolayer under physiologic-like shear stress allowed the conclusion that the majority of tested nanosystems have very good biocompatibility profiles. To understand how the physicochemical features of nanoparticles can affect the specific cellular responses, we are currently investigating the functional effects of the described nanosystems in endothelial and monocytic cells. These studies are expected to provide further important information concerning the mechanisms of nanoparticle-elicited cellular effects. Our pilot studies in the pig model confirmed the safety of liposomal formulation (LP-NP1) in vivo, and constitute an important step toward further development and functionalization of these particles for the purpose of intravascular imaging and targeted drug delivery. In the future, substantial amount of in vivo studies will be necessary before the nanosystems with proven in vitro safety and efficacy can be translated into clinical trials. But despite multiple safety and regulatory constraints, the future progress in diagnosis and treatment of cardiovascular disorders is expected to benefit strongly from the development of novel nanotechnology-based strategies.

It must also be noted that cardiovascular disease, including various clinical manifestations of atherosclerosis and thrombosis, is but an example of the disease the therapy of which may profit from intravascular application of nanoparticulate drug carriers. In fact, the majority of the clinically-relevant nanocarriers, such as anticancer and anti-inflammatory nano-drugs, are expected to require intravascular administration. Although the main focus of our work is the diagnosis and therapy of atherosclerosis, the nanosystems investigated in this study constitute a versatile platform, adjustable also for the intravascular drug-delivery in other disease conditions.

\section{Financial \& competing interests disclosure}

This work was supported by the EU ('NanoAthero' project FP7NMP-2012-LARGE-6-309820), the DFG (Cl 162/2-1), and received the financial support from ANR-13-LAB1-0005-01 'FucoChem.' LETI/DTBS is part of the Arcane Labex program, funded by the French National Research Agency (ARCANE project $n^{\circ}$ ANR-12-LABX-003). The authors thank Prof. M. Beckmann (Department of Gynaecology, University Hospital Erlangen, Germany) for providing umbilical cords, N Jaziri for help with HUVEC isolation and P Dörfler for help with flow experiments. The authors have no other relevant affiliations or financial involvement with any organization or entity with a financial interest in or financial conflict with the subject matter or materials discussed in the manuscript apart from those disclosed.

No writing assistance was utilized in the production of this manuscript.

\footnotetext{
Ethical conduct of research

The authors state that they have obtained appropriate institutional review board approval or have followed the principles outlined in the Declaration of Helsinki for all human or animal experimental investigations. In addition, for investigations involving human subjects, informed consent has been obtained from the participants involved.
} 
Executive summary

Background

- Detailed physicochemical and biological characterization of nanosystems in vitro is necessary to ensure their safety in more complex physiological conditions.

Methods

- We investigated 10 diverse nanosystems, comprising liposomes, lipid nanoparticles, polymeric and iron oxide nanoparticles to assess their long-term stability and biological effects on endothelial cells (ECs).

- EC viability in static conditions was monitored using real-time cell analysis and live-cell microscopy.

- A flow model of arterial bifurcations was used to assess the effect of circulating nanoparticles on EC monolayer under physiologic-like shear stress.

Results

- The majority of tested nanosystems were well tolerated by ECs up to the concentration of $100 \mu \mathrm{g} / \mathrm{ml}$ in static, and up to $400 \mu \mathrm{g} / \mathrm{ml}$ in dynamic conditions.

- In static conditions, nanoparticle sedimentation was responsible for the majority of the cytostatic and cytotoxic effects observed below nanoparticle concentration of $200 \mu \mathrm{g} / \mathrm{ml}$.

- The results of a pilot study in a pig model showed that intravenous administration of liposomal nanoparticles did not evoke the hypersensitivity reaction, indicating a low immunogenicity of these nanoparticles.

Conclusion

- The majority of tested nanosystems had an overall favorable biocompatibility profile, constituting good candidates for cardiovascular imaging and drug targeting applications.

\section{References}

Papers of special note have been highlighted as: • of interest; •- of considerable interest

1 Lozano R, Naghavi M, Foreman K et al. Global and regional mortality from 235 causes of death for 20 age groups in 1990 and 2010: a systematic analysis for the Global Burden of Disease Study 2010. Lancet 380 (9859), 2095-2128 (2012).

2 Libby P, Theroux P. Pathophysiology of coronary artery disease. Circulation 111(25), 3481-3488 (2005).

-. The in-depth review of the pathophysiology of atherosclerosis as an inflammatory disease.

3 Mangge H, Almer G, Stelzer I, Reininghaus E, Prassl R. Laboratory medicine for molecular imaging of atherosclerosis. Clin. Chim. Acta 437 19-24 (2014).

4 Cicha I, Garlichs CD, Alexiou C. Cardiovascular therapy through nanotechnology - how far are we still from bedside? Eur. J. Nanomed. 6(2), 63-87 (2014).

- This review highlights the recent advances in the preclinical and clinical applications of nanoparticulate agents for cardiovascular diagnostics and therapy.

5 Cicha I, Lyer S, Alexiou C, Garlichs CD. Nanomedicine in diagnostics and therapy of cardiovascular diseases: beyond atherosclerotic plaque imaging. Nanotechnol. Rev. 2(4), 449-472 (2013).

6 Neves AR, Queiroz JF, Weksler B, Romero IA, Couraud PO, Reis S. Solid lipid nanoparticles as a vehicle for brain-targeted drug delivery: two new strategies of functionalization with apolipoprotein E. Nanotechnology 26(49), 495103 (2015).

7 Kennedy IM, Wilson D, Barakat AI, Committee HEIHR. Uptake and inflammatory effects of nanoparticles in a human vascular endothelial cell line. Research Rep. (136), 3-32 (2009).
8 Battaglia L, Gallarate M, Peira E et al. Bevacizumab loaded solid lipid nanoparticles prepared by the coacervation technique: preliminary in vitro studies. Nanotechnology 26(25), 255102 (2015).

9 Dan M, Scott DF, Hardy PA et al. Block copolymer cross-linked nanoassemblies improve particle stability and biocompatibility of superparamagnetic iron oxide nanoparticles. Pharmaceut. Res. 30(2), 552-561 (2013).

10 Gravier J, Navarro FP, Delmas T et al. Lipidots: competitive organic alternative to quantum dots for in vivo fluorescence imaging. J. Biomed. Opt. 16(9), 096013 (2011).

11 Puri A, Loomis K, Smith B et al. Lipid-based nanoparticles as pharmaceutical drug carriers: from concepts to clinic. Crit. Rev. Therapeut. Drug Carrier Syst. 26(6), 523-580 (2009).

12 Almer G, Frascione D, Pali-Scholl I et al. Interleukin-10: an anti-inflammatory marker to target atherosclerotic lesions via PEGylated liposomes. Mol. Pharmaceut. 10(1), 175-186 (2013).

13 Huwyler J, Drewe J, Krahenbuhl S. Tumor targeting using liposomal antineoplastic drugs. Int. J. Nanomedicine 3(1), 21-29 (2008).

14 Muller RH, Shegokar R, Keck CM. 20 years of lipid nanoparticles (SLN and NLC): present state of development and industrial applications. Curr. drug Discov. Technol. 8(3), 207-227 (2011).

15 Bachelet L, Bertholon I, Lavigne D et al. Affinity of low molecular weight fucoidan for P-selectin triggers its binding to activated human platelets. Biochim. Biophys. acta 1790 (2), 141-146 (2009).

16 Rouzet F, Bachelet-Violette L, Alsac JM et al. Radiolabeled fucoidan as a p-selectin targeting agent for in vivo imaging of platelet-rich thrombus and endothelial activation. J. Nucl. Med. 52(9), 1433-1440 (2011). 
17 Trivedi RA, Mallawarachi C, Jm UK-I et al. Identifying inflamed carotid plaques using in vivo USPIO-enhanced MR imaging to label plaque macrophages. Arterioscl. Thromb. Vasc. Biol. 26(7), 1601-1606 (2006).

18 Howarth SP, Tang TY, Trivedi R et al. Utility of USPIOenhanced MR imaging to identify inflammation and the fibrous cap: a comparison of symptomatic and asymptomatic individuals. Eur. J. Radiol. 70 (3), 555-560 (2009).

19 Tang TY, Muller KH, Graves MJ et al. Iron oxide particles for atheroma imaging. Arterioscl. Thromb. Vasc. Biol. 29(7), 1001-1008 (2009).

20 Sadat U, Howarth SP, Usman A, Tang TY, Graves MJ, Gillard JH. Sequential imaging of asymptomatic carotid atheroma using ultrasmall superparamagnetic iron oxideenhanced magnetic resonance imaging: a feasibility study. J. Stroke Cerebrovasc. Dis. 22(8), e271-276 (2013).

21 Janko C, Durr S, Munoz LE et al. Magnetic drug targeting reduces the chemotherapeutic burden on circulating leukocytes. Int. J. Mol. Sci. 14(4), 7341-7355 (2013).

22 Lyer S, Tietze R, Jurgons R et al. Visualisation of tumour regression after local chemotherapy with magnetic nanoparticles - a pilot study. Anticancer Res. 30(5), 1553-1557 (2010).

23 Tietze R, Lyer S, Durr S et al. Efficient drug-delivery using magnetic nanoparticles - biodistribution and therapeutic effects in tumour bearing rabbits. Nanomedicine 9(7), 961-971 (2013).

- This article presents the results of the world's largest animal study to date, investigating the efficacy of magnetic drug targeting using mitoxantrone-loaded SPIONS in tumor-bearing rabbits.

24 Kumar A, Dhawan A. Genotoxic and carcinogenic potential of engineered nanoparticles: an update. Arch. Toxicol. 87(11), 1883-1900 (2013).

25 Zolnik BS, Gonzalez-Fernandez A, Sadrieh N, Dobrovolskaia MA. Nanoparticles and the immune system. Endocrinology 151(2), 458-465 (2010).

26 Ong KJ, Maccormack TJ, Clark RJ et al. Widespread nanoparticle-assay interference: implications for nanotoxicity testing. PLos ONE 9(3), e90650 (2014).

-• Important contribution to the issue of nanoparticle interference with toxicity assays. This article also provides guidance on controlling for such interference to improve the accuracy of nanotoxicity assessments.

27 Almer G, Wernig K, Saba-Lepek M et al. Adiponectincoated nanoparticles for enhanced imaging of atherosclerotic plaques. Int. J. Nanomedicine 6, 1279-1290 (2011).

28 Zaloga J, Janko C, Nowak J et al. Development of a lauric acid/albumin hybrid iron oxide nanoparticle system with improved biocompatibility. Int. J. Nanomedicine 9, 4847-4866 (2014).

29 Unterweger H, Tietze R, Janko C et al. Development and characterization of magnetic iron oxide nanoparticles with a cisplatin-bearing polymer coating for targeted drug delivery. Int. J. Nanomedicine 9, 3659-3676 (2014).
30 Matuszak J, Zaloga J, Friedrich RP et al. Endothelial biocompatibility and accumulation of SPION under flow conditions. J. Magn. Magn. Mater. 380, 20-26 (2015).

31 Cicha I, Beronov K, Ramirez EL et al. Shear stress preconditioning modulates endothelial susceptibility to circulating TNF-alpha and monocytic cell recruitment in a simplified model of arterial bifurcations. Atherosclerosis 207(1), 93-102 (2009).

32 Szebeni J. Complement activation-related pseudoallergy: a stress reaction in blood triggered by nanomedicines and biologicals. Mol. Immunol. 61(2), 163-173 (2014).

-• This review provides basic information on complement activation-related pseudoallergy (CARPA), including a short history, incidence, classification of CARPA-genic drugs and symptoms, and the mechanisms of $\mathrm{C}$ activation via different pathways.

33 Durr S, Lyer S, Mann J et al. Real-time cell analysis of human cancer cell lines after chemotherapy with functionalized magnetic nanoparticles. Anticancer Res. 32(5), 1983-1989 (2012).

34 Fede C, Fortunati I, Weber V et al. Evaluation of gold nanoparticles toxicity towards human endothelial cells under static and flow conditions. Microvasc. Res. 97, 147-155 (2015).

35 Rinkenauer AC, Press AT, Raasch M et al. Comparison of the uptake of methacrylate-based nanoparticles in static and dynamic in vitro systems as well as in vivo. J. Control. Release 216, 158-168 (2015).

36 Klingberg H, Loft S, Oddershede LB, Moller P. The influence of flow, shear stress and adhesion molecule targeting on gold nanoparticle uptake in human endothelial cells. Nanoscale 7(26), 11409-11419 (2015).

37 Cooper JD, Mcdonald JWD, Ali M, Menkes E, Masterson J, Klement P. Prostaglandin production associated with the pulmonary vascular-response to complement activation. Surgery 88(2), 215-221 (1980).

38 Szebeni J, Fontana JL, Wassef NM et al. Hemodynamic changes induced by liposomes and liposome-encapsulated hemoglobin in pigs - A model for pseudoallergic cardiopulmonary reactions to liposomes: role of complement and inhibition by soluble CR1 and anti-C5a antibody. Circulation 99(17), 2302-2309 (1999).

39 Desai N. Challenges in development of nanoparticle-based therapeutics. AAPS J. 14(2), 282-295 (2012).

40 Aillon KL, Xie Y, El-Gendy N, Berkland CJ, Forrest ML. Effects of nanomaterial physicochemical properties on in vivo toxicity. Adv. Drug Deliv. Rev. 61(6), 457-466 (2009).

41 Oberdorster G. Safety assessment for nanotechnology and nanomedicine: concepts of nanotoxicology. J. Intern. Med. 267(1), 89-105 (2010).

42 Hirsjarvi S, Dufort S, Gravier J et al. Influence of size, surface coating and fine chemical composition on the in vitro reactivity and in vivo biodistribution of lipid nanocapsules versus lipid nanoemulsions in cancer models. Nanomedicine 9(3), 375-387 (2013).

43 Keene AM, Allaway RJ, Sadrieh N, Tyner KM. Gold nanoparticle trafficking of typically excluded compounds 
across the cell membrane in JB6 $\mathrm{Cl} 41-5$ a cells causes assay interference. Nanotoxicology 5(4), 469-478 (2011).

44 Monteiro-Riviere NA, Inman AO, Zhang LW. Limitations and relative utility of screening assays to assess engineered nanoparticle toxicity in a human cell line. Toxicol. Appl. Pharmacol. 234(2), 222-235 (2009).

45 Lira MCB, Santos-Magalhaes NS, Nicolas V et al. Cytotoxicity and cellular uptake of newly synthesized fucoidan-coated nanoparticles. Eur. J. Pharmaceut. Biopharmaceut. 79(1), 162-170 (2011).

46 Coimbra M, Banciu M, Fens MH et al. Liposomal pravastatin inhibits tumor growth by targeting cancer-related inflammation. J. Control. Release 148(3), 303-310 (2010).

47 Orlando A, Re F, Sesana $S$ et al. Effect of nanoparticles binding beta-amyloid peptide on nitric oxide production by cultured endothelial cells and macrophages. Int. J. Nanomedicine 8, 1335-1347 (2013).

48 Soenen SJ, De Cuyper M. Assessing iron oxide nanoparticle toxicity in vitro: current status and future prospects. Nanomedicine (Lond.) 5(8), 1261-1275 (2010).

- This work presents an overview of different types of iron oxide nanoparticles developed for biomedical research with particular focus on their internalization and cytotoxicity.
49 Mahmoudi M, Hofmann H, Rothen-Rutishauser B, Petri-Fink A. Assessing the in vitro and in vivo toxicity of superparamagnetic iron oxide nanoparticles. Chemical Rev. 112(4), 2323-2338 (2012).

50 Yu M, Huang S, Yu KJ, Clyne AM. Dextran and polymer polyethylene glycol (PEG) coating reduce both 5 and $30 \mathrm{~nm}$ iron oxide nanoparticle cytotoxicity in 2D and 3D cell culture. Int. J. Mol. Sci. 13(5), 5554-5570 (2012).

51 Buyukhatipoglu K, Clyne AM. Superparamagnetic iron oxide nanoparticles change endothelial cell morphology and mechanics via reactive oxygen species formation. J. Biomed. Mater. Res. A 96A(1), 186-195 (2011).

52 Li M, Kim HS, Tian L, Yu MK, Jon S, Moon WK. Comparison of two ultrasmall superparamagnetic iron oxides on cytotoxicity and MR imaging of tumors. Theranostics 2(1), 76-85 (2012).

53 Szebeni J, Bedocs P, Csukas D, Rosivall L, Bunger R, Urbanics R. A porcine model of complement-mediated infusion reactions to drug carrier nanosystems and other medicines. Adv. Drug Deliv. Rev. 64(15), 1706-1716 (2012). 